\title{
Assessing the Performance of Funds of Hedge Funds
}

\author{
B. Dewaele, H. Pirotte, N. Tuchschmid and \\ E. Wallerstein
}

This paper studies the performance of a sample of funds of hedge funds (FoHFs) from January 1994 to August 2009. We apply the false discoveries (FD) technique of Barras, Scaillet and Wermers (2010) to separate the FoHFs into skilled, zero-alpha and unskilled. We measure the alpha of the FoHFs using two models - (1) a 16-factor model with a combination of factors from Fung and Hsieh (2004) and Capocci, Corhay and Hübner (2005) and (2) a 13-factor model of hedge fund indices from Dow Jones Credit Suisse. Applying the FD procedure to the first model, we find that, after fees, the majority of FoHFs do not channel alpha from single-manager hedge funds. Applying the FD procedure to the second model, we find that only a very small fraction of FoHFs deliver after-fees alpha per se, i.e. on top of the alpha of the hedge fund indices. A series of robustness checks confirms the results of the FD procedure. We also compare the performance of our sample of FoHFs to artificial FoHFs constructed by randomly picking hedge funds. The lack of significant differences in the average performance of the real and artificial FoHFs confirms the results obtained by the FD procedure.

JEL Classifications: G11, G15, C14.

Keywords: Hedge funds, funds of funds, selection bias, abnormal returns, zeroalpha, skilled and unskilled performance, false discoveries.

\section{CEB Working Paper $N^{\circ} 11 / 041$ September 2011}




\title{
Assessing the Performance of Funds of Hedge Funds*
}

\author{
B. Dewaele ${ }^{a}$, H. Pirotte ${ }^{b}$, N. Tuchschmid ${ }^{c}$, E. Wallerstein ${ }^{d}$
}

This version: September 16, 2011

\begin{abstract}
This paper studies the performance of a sample of funds of hedge funds (FoHFs) from January 1994 to August 2009. We apply the false discoveries (FD) technique of Barras, Scaillet and Wermers (2010) to separate the FoHFs into skilled, zero-alpha and unskilled. We measure the alpha of the FoHFs using two models - (1) a 16-factor model with a combination of factors from Fung and Hsieh (2004) and Capocci, Corhay and Hübner (2005) and (2) a 13-factor model of hedge fund indices from Dow Jones Credit Suisse. Applying the FD procedure to the first model, we find that, after fees, the majority of FoHFs do not channel alpha from single-manager hedge funds. Applying the FD procedure to the second model, we find that only a very small fraction of FoHFs deliver after-fees alpha per se, i.e. on top of the alpha of the hedge fund indices. A series of robustness checks confirms the results of the FD procedure. We also compare the performance of our sample of FoHFs to artificial FoHFs constructed by randomly picking hedge funds. The lack of significant differences in the average performance of the real and artificial FoHFs confirms the results obtained by the FD procedure.
\end{abstract}

KeyWorDs: Hedge funds, funds of funds, selection bias, abnormal returns, zero-alpha, skilled and unskilled performance, false discoveries.

JEL classification: G11, G15, C14.

\section{Introduction}

Hedge funds are lightly regulated investment vehicles that invest in a broad range of assets using a wide variety of investment strategies and usually targeting absolute returns. The growth of the number of hedge funds and the assets under management (AUM) of the hedge fund industry over the past two decades has attracted a lot of scholarly attention. Fung and Hsieh (1997, 2001, 2004), Agarwal and Naik (2004), Capocci et al. (2005), and a host of other authors have contributed to the study of the performance of hedge funds.

The present article focuses on the historical performance of funds of hedge funds (FoHFs), i.e., funds that invest in portfolios of hedge funds. According to BarclayHedge ${ }^{1}$, the

\footnotetext{
* This research has benefited from the financial support of the BNP Paribas Fortis Chair in Banking of the Solvay Brussels School and RCSO Management (HES-SO Project No. SAGE - X 24244), and from the data of Thomson Reuters. We would like to extend our gratitude to BNP Paribas Fortis, RCSO Management, Banque SYZ. We especially thank Iliya Markov for his research assistance.

a Centre E. Bernheim, Solvay Brussels School of Economics and Management, University of Brussels, av F.D. Roosevelt 21, CP 145/01, B-1050 Brussels, Belgium. Contact author: bedewael@ulb.ac.be

b Centre E. Bernheim, Solvay Brussels School of Economics and Management, University of Brussels, av F.D. Roosevelt 21, CP 145/01, B-1050 Brussels, Belgium.

c Tages Capital, London and Haute Ecole de Gestion de Genève, Campus de Battelle, Bâtiment F, route de Drize 7, CH-1227 Carouge, Switzerland.

d Credit Suisse, Uetlibergstrasse 132, CH-8070 Zürich, Switzerland

${ }^{1}$ BarclayHedge website : http://www.barclayhedge.com
} 
global hedge fund industry (excluding FoHFs) has grown from $\$ 151$ billion in AUM in 1997 to $\$ 1 ' 962$ billion in 2010 , with a peak of $\$ 2 ' 343$ in 2007 . The FoHFs industry, on the other hand, has grown from $\$ 55$ billion in AUM in 1997 to $\$ 562$ billion in 2010, with a peak of $\$ 1 ' 192$ billion in 2007. The numbers indicate that between 1997 and 2007, the total AUM of the hedge fund industry has grown roughly 14 times, while that of the FoHFs industry has grown more than 20 times. If we extend this period until 2010, however, we see a different picture, with FoHFs exhibiting a lower level of growth due to the significant asset outflows in 2008 and 2009.

FoHFs provide investors with access to the hedge fund market whilst adding diversification and therefore reducing fund-specific risk. They also aim at fostering more transparency by monitoring the activities of the underlying hedge fund managers. What is more, many FoHFs have investments in single-manager hedge funds that are already closed to new investments. The latters being run by the most successful managers, at least in attracting investors, FoHFs claim that they can thus bring benefits to investors by providing access to those managers.

Based on their own claims, FoHFs should be expected to invest in the best singlemanager hedge funds and/or to have a good market timing among the various hedge funds strategies available thus delivering regular alpha to their investors with the added advantage of diversification. FoHFs, however, charge an additional layer of fees, above that already charged by the individual hedge funds. A study of the performance of FoHFs should thus aim to answer two questions. Firstly, it should look into whether FoHF managers deliver, or channel, after-fees alpha from single-manager hedge funds. Secondly, it should also look into whether FoHFs can produce any alpha above that already delivered by the universe of single-manager hedge funds, i.e. whether there is any FoHF manager added value after management and incentive fees are subtracted.

In addition, the study of FoHFs gives a more accurate representation of the returns earned by hedge fund investors. As Fung and Hsieh (2008) suggest, studying the performance of FoHFs has several advantages compared to studying the performance of single-manager hedge funds. FoHFs include the returns of hedge funds on the brink of collapse that would otherwise stop reporting to a database several months before their actual collapse. Moreover, in case such hedge funds collapse, the FoHFs will most probably survive as they are invested in a diversified portfolio of underlying funds. Fung and Hsieh (2008) also point out that FoHF performance reflects real-life restrictions that hedge fund investors are exposed to, for example the constraint on immediate capital withdrawal. The performance of FoHFs, therefore, gives a more accurate picture of the downside risk faced by hedge fund investors.

The present article studies the performance of a sample of FoHFs for the period from January 1994 to August 2009. In line with the above arguments, we use two regression models: (a) a 16-factor asset-based style model which allows us to assess the alphachannelling skills of FoHFs and (b) a 13-factor model of hedge fund indices which allows us to establish whether FoHFs deliver alpha per se. We apply the false discoveries (FD) technique proposed by Barras et al. (2010) to separate truly skilled from zero-alpha and truly unskilled FoHFs. The results of the FD procedure show that $21.17 \%$ of FoHF managers channel after-fees alpha but only $5.56 \%$ deliver alpha above the alpha of the 
hedge fund indices. What is more, $47.50 \%$ of FoHFs managers deliver negative after-fees alpha when benchmarked against the hedge fund indices. We confirm the results of the FD procedure through a series of robustness checks. We also conduct an experiment which compares the performance of our sample FoHFs to artificial FoHFs constructed by randomly picking constituent hedge funds. It shows that there is no meaningful difference between the performance of real and artificial FoHFs. On the one hand, this result is a confirmation of the results of the FD procedure. On the other hand, it comes to show that FoHF managers do not exhibit hedge fund picking or strategy-timing skills even before controlling for the fees they charge.

This paper is organized as follows : Section 2 reviews previous work on the performance of mutual funds, hedge funds and FoHFs and discusses the historical development of performance assessment tools. Section 3 describes our data set and comments on the most important biases we have managed to avoid. Section 4 describes the methodology we have used in assessing the performance of FoHFs with section 5 presenting our results. Section 6 describes the various robustness checks we have performed. Section 7 concludes.

\section{Literature Review}

For the purpose of assessing managerial skills, investment returns are decomposed into the part that can be replicated using a standard basket of assets - or a market index - and the residual, or alpha, which is attributed to the fund manager's skills. The modelling of investment returns dates back to the middle of the twentieth century. Jensen (1968) uses a simple one-factor asset pricing model, which he uses to regress mutual fund returns on the market returns. Later, Fama and French (1993) propose a three-factor asset pricing model by taking into account size and the book-to-market ratio. Carhart (1997) extends their model by adding a momentum factor.

\subsection{Early Research}

Using a different approach, Sharpe (1992) applies style analysis to mutual funds' returns and observes that their strategies have significant exposures to certain equity and fixed income indices, which almost entirely explain the funds' return variations. Sharpe (1992) thus demonstrates that mutual fund strategies can be very well described by only a limited set of asset classes. On the other hand, applying Sharpe's (1992) asset-class factor model to hedge fund returns would imply that a large part of hedge fund returns comes from the manager skill.

As Fung and Hsieh (1997) observe, however, hedge fund returns tend to be far less correlated to the standard asset classes and the latter do not play a major role in determining hedge funds' performance. Fung and Hsieh (1997) develop an asset-class factor ${ }^{2}$ model which produces a more detailed breakdown of the component of skill in order to further characterize the performance differences among different groups of hedge funds. The authors conclude that there are 12 important investment styles - buy-and-hold strategies in 9 asset classes and 3 dynamic trading strategies. Fung and Hsieh (1997) believe that these

\footnotetext{
${ }^{2}$ In line with Sharpe's terminology
} 
12 factors should produce a reasonably high adjusted $R^{2}$ for $85 \%$ of mutual funds and $40 \%$ of hedge funds, and should provide a good starting point for the analysis of both relative (mutual funds) and absolute (hedge funds) return managers.

Liang (1999) confirms Fung and Hsieh's (1997) observation that hedge fund returns differ substantially from those of traditional investment vehicles. He uses an asset-class factor model similar to the ones used by Sharpe (1992) and Fung and Hsieh (1997). He too finds relatively low correlations between the returns of hedge funds and those of the standard asset classes. The low betas show that hedge funds are less correlated to equities and other traditional investments. The non-zero betas, on the other hand, indicate that hedge funds do not actually hedge positions (as their name implies) by simply entering into long and short contracts. In short, Liang (1999) confirms Fung and Hsieh's (1997) finding that hedge funds apply dynamic trading strategies in various markets.

\subsection{Modelling hedge fund returns}

In a subsequent paper, Fung and Hsieh (2004) reaffirm the difficulties in assessing hedge fund returns using traditional asset classes. Their article proposes a model of hedge fund returns similar to models based on arbitrage pricing theory with dynamic risk-factor coefficients. Their model accounts for beta non-linearities in the performance of hedge funds and shows very high explanatory power in assessing the performance of portfolios of hedge funds proxied by hedge fund indices.

After analysing the risk profiles of different groups of hedge funds in terms of strategy, the authors propose a 7 -factor asset-based style (ABS) model. The various factors in the model pertain to particular hedge fund strategies. Market risk and the spread between small cap stocks and large cap stocks are important for long-short equity funds. The change in the $10 \mathrm{yr}$. Treasury yield and the change in the spread between the latter and Moody's BAA bonds are important for fixed income funds. Portfolios of lookback straddles on currencies, bonds and commodities are important for trend following funds. Yet, the authors admit that these seven factors are found in $57 \%$ of the hedge funds in the Lipper TASS database (TASS) and a mere $37 \%$ of the hedge funds in the Hedge Fund Research database (HFR).

There are several important observations that Fung and Hsieh (2004) make using their ABS model for the sample period from 1994 to 2002. First, they find significant alphas for four equally-weighted and value-weighted hedge fund indices. Second, they find that alpha tends to decrease over time, implying that manager skill is diminishing. This point is corroborated by subsequent research by other authors as well. Third, HFRFOF - the index of FoHFs - exhibits lower alpha when compared to the hedge fund indices. The most likely reason for this fact, the authors suggest, is that HFRFOF simply reflects too many inefficient hedge funds.

In the same spirit, Capocci et al. (2005) also confirm the low correlations of hedge funds to traditional asset factors. They design an original 10-factor model for assessing the performance of hedge funds. Their model achieves very high significance levels and shows that during the whole sample period from 1994 to $2002^{3}$ the hedge fund industry

\footnotetext{
${ }^{3}$ Similar to that of Fung and Hsieh (2004).
} 
outperformed the market ${ }^{4}$. The authors insist that even though their model might seem over-specified, hedge funds are very heterogeneous and unlike mutual funds invest in many assets and in various markets. Their model includes factors coming from Fama and French (1993), Carhart (1997), Agarwal and Naik (2004) and Capocci and Hübner (2004).

The authors confirm that all of the additional factors add to the explanatory power of the model and improve it compared to Carhart's (1997) model and the standard CAPM. The authors explain that although adding more factors to the model reduces alpha, the average adjusted $R^{2}$ for the entire sample period goes from $61 \%$ for the CAPM, through $80 \%$ for Carhart's model to $84 \%$ for their 10 -factor model. The authors claim that this is the highest value achieved by that time (2005). Interestingly, similar to Fung and Hsieh (2004), Capocci et al. (2005) find lower alpha for FoHFs compared to single-manager hedge funds. In addition, both the Fung and Hsieh (2004) and Capocci et al. (2005) models exhibit lower explanatory power when applied to FoHFs than when applied to single-manager hedge funds.

Philipp et al. (2009) use a 3-component score with the purpose of attaching a performance rating score to the FoHFs in the hedgegate ${ }^{5}$ database. Their 3-component score takes into account the market returns, the manager skill as measured by the alpha, and the risk of extreme losses as measured by the $\mathrm{CVaR}^{6}$. To calculate the alpha, Philipp et al. use a 19-factor regression model with three main groups of regressors - money market instruments, financial instruments and derivatives.

For each FoHF in the database, the authors use the last 48 monthly returns. This accounts for the fact that FoHF managers alter their strategies in response to market changes. In each regression round, only the statistically significant factors are kept. The alphas calculated with the regressions are combined with the market returns and the CVaRs to yield a composite score for the FoHFs' performance. In the final score, market return and the alpha are given an equal weight of one, and the sum is normalized by dividing by the CVaR. Using this model, the authors observe that during "calm" times (from 2005 to 2007) the effects of market returns and manager skill on the performance of FoHFs are almost of equal magnitude. During "turbulent" times (the dotcom bubble burst and the recent financial crisis), however, the management component has a greater influence on the performance of FoHFs.

\subsection{Controlling for non-normalities and luck in estimated alphas}

Kosowski et al. (2006) apply a new bootstrap methodology to measure the performance of U.S. open-end domestic equity mutual funds for the period from 1975 to 2002. They ground the need for a bootstrap procedure on the fact that both the cross-section of mutual funds and individual mutual funds have alphas with complex non-normal distributions. Bootstrapping thus more successfully captures the complex shape of the entire crosssectional distribution. In a nutshell, Kosowski et al. (2006) examine the performance of

\footnotetext{
${ }^{4}$ Although mostly due to the superior performance during the bullish sub-period from 1994 to 2000.

${ }^{5}$ Hedgegate contains all Swiss-registered funds of hedge funds plus several hundred funds for qualified investors with reference to Swiss investors.

${ }^{6} \mathrm{CVaR}$ stands for conditional value at risk. For modelling CVaR the authors use the normal-inverse Gaussian distribution because of its sufficient flexibility to map asymmetries and extreme losses in FoHFs returns.
} 
mutual funds without imposing an ex-ante distribution from which mutual funds' returns are drawn.

Later Fung et al. (2008) conduct an extensive study on the performance of FoHFs for the period from 1995 to 2004. Using their 7-factor model and accounting for structural breaks (the fall of LTCM in 1998 and the NASDAQ crash in 2000) the authors find that the average FoHFs only delivers alpha between 1998 and 2000. Their original 7-factor model shows very high explanatory power with an adjusted $R^{2}$ equal to $74 \%$. Using the Kosowski et al. (2006) bootstrap procedure on the alpha detected by their model, Fung et al. (2008) identify that, for their sample and testing period, $22 \%$ of FoHFs on average exhibit alphadelivering skills.

Criton and Scaillet (2009) propose a time-varying coefficient model with eight factors from Fung and Hsieh (2004) ${ }^{7}$ which they apply to a large sample of hedge funds for a sample period from January 1994 to July 2007. Criton and Scaillet (2009) apply the false discoveries (FD) methodology developed by Barras et al. (2010) to separate their population of hedge funds into skilled, unskilled and zero-alpha ${ }^{8}$. A classical inference procedure would identify as skilled, zero-alpha funds that reject the null hypothesis by luck on the right tail of the zero-alpha distribution. By the same token, it would identify as unskilled, funds that reject the null hypothesis by misfortune on the left tail of the zero-alpha distribution. Recognizing that zero-alpha, skilled and unskilled funds have their own distributions, Barras et al. (2010) derive the proportions of truly skilled, truly unskilled and zero-alpha funds by correcting for the two cases above. Applying the Barras et al. (2010) bootstrap procedure, Criton and Scaillet (2009) find significant proportions of both skilled and unskilled hedge funds. In comparison to Barras et al. (2010) who apply their methodology to U.S. open-end equity mutual funds, Criton and Scaillet (2009) find a much larger proportion of skilled hedge funds.

The primary contribution of the present article is the analysis of alpha by controlling for luck in the case of FoHFs. Our research draws from much of the previous literature on the topic described in this section. We use a 16 -factor $(16 \mathrm{~F})$ model with factors chosen from Fung and Hsieh (2004) and Capocci et al (2005). We also use a regression model with 13 hedge fund indices provided by Dow Jones Credit Suisse (DJCS) in order to establish whether FoHFs can generate alpha per se, or whether the alpha detected by the first regression is only due to the performance of the single-manager hedge funds that the FoHFs have invested in. Applying the abovementioned methodology of Barras et al. (2010) to the alpha of both regressions, we separate the FoHFs into zero-alpha, skilled and unskilled. The results show that most FoHFs do not exhibit alpha, especially when we control for the alpha already delivered by the universe of single-manager hedge funds. In addition, we also perform an experiment, which compares the performance of our sample of FoHFs to a sample of randomly constructed FoHFs. The results of this experiment show that the difference in performance between real and artificial FoHFs is negligible. Thus we both confirm the results already obtained by the FD procedure and question the fund picking and strategy timing skills of FoHFs before fees are subtracted.

\footnotetext{
7 The original seven factors from Fung and Hsieh (2004) plus the MSCI Emerging Markets Index as later suggested on David Hsieh's webpage.

${ }^{8}$ Note that Barras, Scaillet and Wermers (2010) was available as a working paper in 2008. Criton and Scaillet (2009) therefore refer to Barras, Scaillet and Wermers (2008).
} 


\section{Data}

The data used in this paper were collected from the Lipper TASS database and include hedge funds' and FoHFs' monthly net-of-fees return histories from January 1994 to August 2009. Our database contains both active and defunct funds, eliminating à priori problems due to survivorship bias in our selection. Similar to Liang (1999), we decided to delete funds reporting returns quarterly. We also deleted funds with outliers ${ }^{9}$. As suggested by Fung and Hsieh (1997) and many others, we deleted duplicated funds, as they are essentially similar series of the same funds offered as different share classes for regulatory and accounting reasons (step B).

As will be explained below, backfilling or instant history bias, is immediately corrected in our database by deleting the returns between the inception date of the fund and the date the fund was added to TASS. To avoid introducing an additional bias to our database, we decided to delete the funds for which information about the inception or registration date is missing (step C). Additionally, we decided to treat only funds whose returns are reported in USD (step D) (In the cases where not all returns were reported in USD, we used data on all currencies and converted them to USD. This approach does not affect our results qualitatively). Our data sample thus contains 1'315 FoHFs. Table 1 summarizes the treatments applied to the original data.

Table 1

Database "cleaning" details

This table shows the total number of hedge funds and the number of FoHFs that remain after applying cumulatively each treatment to the original data.

\begin{tabular}{llll}
\hline Item & Sampling & Total Funds & FoHFs \\
\hline A) & Total sample & $13^{\prime} 431$ & $4^{\prime} 564$ \\
B) & After careful eliminations ${ }^{10}$ & $8^{\prime} 286$ & $2^{\prime} 309$ \\
C) & No info on date of addition & $7^{\prime} 299$ & $2^{\prime} 008$ \\
D) & In USD $^{11}$ & $5^{\prime} 559$ & $1^{\prime} 315$ \\
\hline
\end{tabular}

Table 2 below gives the strategy breakdown of all the funds available in step D) of the procedure described above. We can see that FoHFs make up a significant portion of the hedge fund industry, both in absolute numbers and percentage-wise. TASS also provides the funds' reasons for withdrawal from the database. Table 3 gives the numbers and percentages of active FoHFs and FoHFs that withdrew from TASS for various reasons. From this point on, this article will concentrate on the sample of FoHFs presented in table 3.

\footnotetext{
${ }^{9}$ By outliers, we mean returns which more than likely come from coding errors.

${ }^{10}$ Following the methodology of Fung and Hsieh (1997), "careful eliminations" stands for the suppression of (a) redundant funds, i.e. mostly series of the same fund, (b) funds with quarterly returns instead of monthly returns, and (c) funds with aberrant observations.

${ }^{11}$ We kept only the USD denominated versions of each fund to avoid introducing currency risk in our comparisons and having related lines of the same strategy and management firm.
} 
Table 2

Fund strategy statistics

This table shows the number and percentage of hedge funds of different strategy classes. The statistics below pertain to the sample at step D) of Table 1.

\begin{tabular}{lcc}
\hline Strategy & Number of funds & $\begin{array}{c}\text { Percentage of the } \\
\text { sample (\%) }\end{array}$ \\
\hline Convertible Arbitrage & 140 & 2.52 \\
Dedicated Short Bias & 35 & 0.63 \\
Emerging Markets & 434 & 7.81 \\
Equity Market Neutral & 287 & 5.16 \\
Event Driven & 423 & 7.61 \\
Fixed Income Arbitrage & 227 & 4.08 \\
Global Macro & 296 & 5.32 \\
Long/Short Equity Hedge & $1^{\prime} 575$ & 28.33 \\
Managed Futures & 464 & 8.35 \\
Multi-Strategy & 332 & 5.97 \\
Options Strategy & 9 & 0.16 \\
Other & 21 & 0.38 \\
Undefined & 1 & 0.02 \\
FoHFs & $1^{\prime} 315$ & 23.66 \\
\hline Total & $5^{\prime} 559$ & 100.00 \\
\hline
\end{tabular}

Table 3

FoHFs' Withdrawal Reasons

This table shows the number and percentage of active FoHFs and of FoHFs that have withdrawn from the database due to various reasons. The statistics below pertain to the sample of FoHFs at step D) of Table 1.

\begin{tabular}{lcc}
\hline FoHFs drop reason & Number of FoHFs & $\begin{array}{c}\text { Percentage of the } \\
\text { sample (\%) }\end{array}$ \\
\hline Alive & $1^{\prime} 038$ & 78.94 \\
Fund closed to new investment & 0 & 0.00 \\
Fund dormant & 2 & 0.15 \\
Fund has merged into another entity & 9 & 0.68 \\
Fund liquidated & 96 & 7.30 \\
Fund no longer reporting & 131 & 9.96 \\
Programme closed & 0 & 0.00 \\
Unable to contact fund & 31 & 2.36 \\
Unknown & 8 & 0.61 \\
\hline Total & $1 ' 315$ & 100.00 \\
\hline
\end{tabular}

We should mention here that our use of data on FoHFs should theoretically make our database even less biased. Referring to their 2000 paper, Fung and Hsieh (2004) point out that if a FoHF invests in a hedge fund that does not report to any database, the performance of the latter is still included in the performance of the FoHF thus reducing selection bias. If a 
similar hedge fund is closed or liquidated, this is reflected in the historical performance of the FoHF thus reducing survivorship bias. And finally, if a FoHF invests in a hedge fund, the latter's previous history is not included in the database thus reducing instant history bias.

\section{Methodology}

We start by re-applying the well-known regression frameworks of Fung and Hsieh (2004) and Capocci et al. (2005). This allows us to verify the relevance of the proxies used to represent the factors proposed in both approaches in order to obtain the alphas. Since the objective of this paper is to examine if FoHFs have true added value when compared to the universe of single-manager hedge funds, we deem particularly useful to use the approach of false discoveries (FD) recently proposed by Barras et al. (2010).

\subsection{False discovery overview}

Barras et al. (2010) revisit the old idea of measurement of the performance of fund managers and its persistence with the intention to better disentangle truly skilled fund managers from zero-alpha and truly unskilled fund managers by controlling for "false discoveries". The motivation of the proposal of Barras et al. (2010) lingers on the identification of true skilled and unskilled funds, by correcting the usual hypothesis testing implementations. A classical hypothesis test would first infer the distribution of the whole population of funds and then would define the confidence boundaries to classify funds into the three desired categories: (1) unskilled (left tail), (2) zero-alphas, and (3) skilled (right tail). This methodology can lead to identify as skilled, zero-alpha funds that are rejecting the null hypothesis by luck on the right-hand side of the distribution, and as unskilled funds, funds that are rejecting the null hypothesis by misfortune on the left-hand side of the distribution. By accepting the idea that unskilled, zero-alpha, and skilled funds have their own distribution each, we could compare the "tail" cases of the distribution of zero-alpha funds to the two respective distributions of unskilled-only and skilled-only funds. The key challenge is then to find the proportions of each of them in the total population.

This is performed through the following non-parametric methodology:

(a) We obtain the alphas using two (2) models - a 16-factor (16F) model based on a combination of factors chosen from Fung and Hsieh (2004) and Capocci et al. (2005), and a 13-factor model based on hedge fund indices provided by Dow Jones Credit Suisse (DJCS). The second (DJCS) model will allow us to verify if the potential FoHF alphas detected with the $16 \mathrm{~F}$ model is a particularity of FoHFs or of hedge funds as a group.

$$
r_{i, t}=\alpha_{i}+\sum_{j=1}^{k} \beta_{i}^{j} F_{t}^{j}+\epsilon_{i, t}
$$

where $r_{i, t}$ is the return of fund $i$ for period $t, \alpha_{i}$ is the $i$ fund's alpha, $\beta_{i}^{j}$ is the coefficient for factor $j$ and fund $i, F_{t}^{j}$ is the value of the $j$ factor for period $\mathrm{t}$ (k factors in total), and $\epsilon_{i, t}$ is the corresponding residual. 
(b) As shown by Kosowski et al. (2006), alpha $t$-statistics have better statistical properties than the distribution itself of alphas and we therefore rely on the former. Since regression residuals present autocorrelation and heteroskedasticity, we need to use a heteroskedasticity and autocorrelation-consistent (HAC) estimator. As Newey-West $t$ statistics can lead to over-rejection of the null hypothesis in small samples (the mean length of data record is equal to 92 months), we adapt the methodology of Barras et al. (2010) by using $t$-statistics estimated with a Quadratic Spectral (QS) kernel, with a prewhitening of the residuals and a bandwidth parameter selected as in Andrews (1991). This $t$-statistic estimator proves to be more robust when samples are small. Doing so, we obtain alpha $t$-statistics for each FoHF time series separately.

(c) Given that FoHFs' returns are not normally-distributed, we use the residual-only bootstrap methodology advocated by Kosowski et al. (2006) to obtain the alpha pvalues $^{12}$. Instead of relying on a student-t distribution, they build the t-stat distribution under the null hypothesis, i.e. with $\alpha=0$ by construction. The procedure relies on adding back randomly-sampled residuals from the former regression under step (a) to the same regression equation omitting the alpha constant, i.e.

$$
r_{i, t}^{b}=\sum_{j=1}^{k} \hat{\beta}_{i}^{j} F_{t}^{j}+\epsilon_{i, \tilde{t}}^{b}
$$

where $\epsilon_{i, \tilde{t}}^{b}$ is chosen among all $\epsilon_{i, t}$, with replacement, from the residuals of equation (1). $b$ ranges from 1 to 1000, for each fund $i$ and period $t$.

The bootstrapped returns $r_{i, t}^{b}$ are finally regressed against the factors, resulting in an empirical distribution of 1'000 $t$-statistics under the "zero-alpha" hypothesis. The alpha $\mathrm{p}$-value for each fund is obtained by comparing the original $t$-statistic to the distribution obtained here above.

(d) If all funds were zero-alpha, the p-values would be uniformly distributed over the interval $[0,1]$. Using this property, the objective is to choose a threshold level ${ }^{13}\left(\lambda^{*}\right)$ for the p-value, above which funds are considered as being zero-alpha funds. The number of these funds $\widehat{W}\left(\lambda^{*}\right)$ is compared to the total number of funds $M$ and then finally adapted to the whole region by scaling it by $\left(1-\lambda^{*}\right)$, to obtain the total proportion of zero-alpha funds $\hat{\pi}_{0}\left(\lambda^{*}\right)$.

The optimal $\lambda^{*}$ is found using the bootstrap methodology of Storey (2002) advocated by Barras et al. (2010), which relies on the minimization of a mean-square error (MSE) problem.

(e) The previous bootstrapped individual $t$-statistics (step (c) above) for each fund are aggregated together to derive the non-parametric distribution of the cross-section of FoHFs under the hypothesis $\alpha=0$. This distribution allows us to fix thresholds on each side based on various levels of significance to be tested $\left(\gamma^{-}, \gamma^{+}\right)$for unskilled and skilled funds respectively. We obtain the proportions of skilled and unskilled funds by comparing our original funds' $t$-statistics to these thresholds, and correcting these

12 Please see the internet appendix of Barras et al. (2010)

13 We keep here the notation of Barras et al. (2010) for further reference. 
proportions for false discoveries by subtracting $\hat{\pi}_{0}\left(\lambda^{*}\right)^{\gamma} / 2$ on each side, following the previous result. Thanks to a second MSE minimization procedure, the optimal $\gamma^{-*}, \gamma^{+*}$ are found. In order to preserve a total probability of 1 , only one $\gamma^{*}$ is kept and the reciprocal probability is chosen so as to ensure a probability of 1 . For example, if $\operatorname{argmin}\left(\operatorname{MSE}\left(\gamma^{-*}\right), \operatorname{MSE}\left(\gamma^{+*}\right)\right)=\gamma^{-*}$, then the proportion of skilled funds is by deduction $^{14} \hat{\pi}_{+}=1-\hat{\pi}_{0}\left(\lambda^{*}\right)-\hat{\pi}_{-}\left(\gamma^{-*}\right)$.

\subsection{Asset pricing models and alpha measurement}

As already mentioned, we use two models to extract the alpha from the excess monthly returns of our sample of FoHFs. The details of the two models are presented below. The large numbers of factors used in our regressions (i.e. 16 and 13) can raise questions about multicollinearity. Even if we are not overly concerned by multicollinearity, as we focus on alphas, we still checked for it as we recognize that factor coefficients may provide an additional insight in our analysis. To ensure multicollinearity is not an issue, we use the methodology of Belsley, Kuh, and Welsch (1980) who suggest that multicollinearity is an issue when the condition number of the design matrix is above 20 . In our case, condition numbers for the $16 \mathrm{~F}$ and DJCS model are 8.5 and 17.7 respectively ${ }^{15}$.

\section{A. The 16-factor model (16F)}

The 16-factor model proposed here below is based on an intersected combination of factors chosen from both the Fung and Hsieh (2004) and the Capocci et al. (2005) methodologies. The factors are selected on the basis of their explanatory power, pairwise correlation and their relevance for the hedge fund domain. Some of them are common to both seminal methodologies but are not derived from the same proxy data ${ }^{16}$ and are therefore listed below under Fung and Hsieh or Capocci et al. depending on the calculation we have performed.

- Factors based on Fung and Hsieh's (2004) regression framework:

- the monthly change in the difference between the 10-year Treasury constant maturity yield and the 1-month LIBOR (month end-to-month end) (D10Y),

- the change in the credit spread of Moody's BAA bond over the 10-year Treasury bond $(D B A A-10 Y)$,

- the excess returns on a portfolio of lookback options on bonds (PTFSBD), currencies (PTFSFX), and commodities (PTFSCOM) ${ }^{17}$,

- and, as suggested by David Hsieh on his webpage, we also add the excess return on the MSCI Emerging Markets Index (MSCIEM-LIB).

- Factors based on Capocci et al. (2005) and their reason for adding them to the traditional framework of Fung and Hsieh:

- the excess return on the Russell 3000 Index (RUSS3000-LIB), preferred over the S\&P 500 for its wider stock market coverage,

\footnotetext{
14 This is presented in detail in the internet appendix of Barras et al. (2010)

15 For the Fung and Hsieh and Capocci et al. models condition numbers are 3.4 and 5.4 respectively.

${ }^{16}$ In particular the following factors: the US market excess return - where the Russell 3000 Index is used in place of the S\&P 500 Index - and the "small minus big" spread ("size spread" in Hsieh's terminology)

17 These non-linear factors are directly retrieved from David Hsieh's website: http://faculty.fuqua.duke.edu/ dah7/HFRFData.htm
} 
- the "small-minus-big" (SMB), "high-minus-low" (HML) and momentum $(M O M)^{18}$ Fama and French (1993) factors,

- the excess return on the MSCI World ex-US Index (MSCIWEUS-LIB) ${ }^{19}$,

- the excess return on the Barclays Macro Global High Yield Index (LHMGHY-LIB),

- the excess return on the J.P. Morgan Emerging Markets Bond Index Global Composite (JPMEMBI-LIB) ${ }^{20}$,

- the excess return on the S\&P GSCI Commodity Index (GSCIC-LIB) ${ }^{21}$,

- the excess return on the Citigroup World Government Bond Index (CWGBI-LIB) ${ }^{22}$,

- and the excess return on the Lehman Mortgage-Backed Securities Index (MORTG$L I B)$.

The objective of this model is to extract the alpha of FoHFs when traditional hedge fund factors are considered. Results of the regression are reported in Table 4.

\section{B. The 13-factor model on Dow Jones Credit Suisse indices (DJCS)}

The 13-factor model is based on the returns of 12 hedge fund indices provided by Dow Jones Credit Suisse (DJCS) ${ }^{23}$. This model's regressors are the excess returns of the DJCS indices for the following strategies: Convertible Arbitrage (DJCSCA), Dedicated Short Bias (DJCSDSB), Hedge Distressed (DJCSHD), Equity Market Neutral (DJCSEMN), Event Driven (DJCSED), Fixed Income Arbitrage (DJCSFIA), Managed Futures (DJCSMF), Risk Arbitrage (DJCSRA), Emerging Markets (DJCSEM), Global Macro (DJCSGM), Long-Short Equity Hedge (DJCSLSEH) and Multi-Strategy (DJCSMS). The Hedge Funds Composite Index (DJCSHF) completes this set. The DJCSHF factor was introduced because the NAV weights of the various strategies vary through time ${ }^{24}$. Results of the regression are reported in Table 5.

The alphas retrieved through the residuals of this second regression will allow us to check if the FoHF industry can manage to systematically generate alpha per se - i.e. select the best hedge funds among the hedge fund universe — or if the alphas detected in the first regression stem only from individual hedge funds' activity without any added value from FoHFs, once fees are considered ${ }^{25}$. In other words, the alphas of the first regression can be considered as the channelled performance of the underlying hedge funds that the FoHFs have invested in. Regressing the performance of FoHFs on hedge fund indices, on the other hand, allows us to observe whether FoHFs can generate any alpha above that already delivered by the hedge fund universe.

\footnotetext{
18 The values for these factors are directly retrieved from Kenneth French's website.

${ }_{19}$ As its name may be misleading, it is worth noting that this index does not contain any emerging markets data and is therefore complementary to the emerging markets index listed above.

${ }^{20}$ Complementary to the emerging stock market listed above.

${ }^{21}$ Commodities have been used in many versions of APT models (Cauchie et al. (2003) and Cuenot \& Reyes (1992) for example) and represent a key underlying for some hedge fund strategies.

22 The sovereign credit risk represents a key risk exposure since the events such as LTCM's default and the Russian debt default of 1998

${ }^{23}$ Provided by Datastream.

24 The results confirm the added value of this variable in the study.

25 The authors remind that the return series of Lipper TASS are net of fees.
} 


\subsection{Comparison to random selection}

In order to verify the results obtained through the FD approach and potentially identify other dimensions of added value (or added risk) of FoHFs, we decided to compare our sample of FoHFs to randomly-constructed portfolios of single-manager hedge funds through a bootstrapping methodology. We constructed our artificial FoHFs by randomly selecting 15 hedge funds (amongst our universe of 4'244 individual hedge funds), without replacement, at the beginning of each re-balancing period. The weights allocated to the 15 hedge funds in the portfolio then evolve with the returns of the selected hedge funds until the beginning of the next re-balancing period.

At that point, the total value of the portfolio is reallocated on an equally-weighted basis to another set of 15 randomly selected hedge funds (some of the selected hedge funds may be the same as the hedge funds selected in another re-balancing period). If an underlying hedge fund disappears from the database, we simply replace it by another fund different from the hedge funds already present in our artificial FoHF, which means that the part of the FoHF allocated to the new fund will be equal to the part allocated to the previous hedge fund at the time it disappeared. The performances of the artificial FoHFs are therefore the equallyweighted averages of the returns of the underlying hedge funds at the beginning of the rebalancing periods and weighted averages within the rebalancing periods.

To make the comparison between real and randomly constructed FoHFs as fair as possible, we produced a sample of 1'315 artificial FoHFs with the same characteristics as our sample of real 1'315 FoHFs ${ }^{26}$. The starting and ending dates of the artificial FoHFs match the inception and last reporting dates of the real FoHFs in our database (the first artificial FoHF has the same starting and ending date as our first real FoHF and so on). As the TASS database also reports management and incentive fees and the presence of a high watermark, the fees structure of the 1'315 randomly generated FoHFs is also set to the management and incentive fees of the real 1'315 FoHFs (i.e. the performance and management fees of the first artificial FoHF will be set to the fees of the first real FoHF, and if a high watermark applies to the first real FoHF, we apply a high watermark to the first artificial one). As we have no additional information about the duration of the high watermark, we decided to run the high watermark since the inception date (maybe disadvantaging our artificial FoHFs). Performance fees are payable every year since the inception of the fund and are computed as a percentage of the difference between the value of the fund after management fees and the value of the fund after management fees and incentive fees one year earlier or the high watermark if it applies (high watermark is recorded as fund value after management fees and incentive fees). As the management fees payable period is missing for a lot of funds, we decided to pay management fees monthly as a percentage of the net asset value of the fund at the end of the month. The results we obtained suggest that the difference between the performance of the real and the artificial FoHFs is negligible.

26 The FoHFs' fees structure is detailed in Appendix 2. 


\section{Results}

As already explained in section 4, we detect the presence of alpha in our sample of FoHFs by regressing their excess monthly returns using our two regression models - the $16 \mathrm{~F}$ model with factors combined from Fung and Hsieh (2004) and Capocci at al. (2005) and the DJCS model of hedge fund indices. This section provides the results of the false discoveries (FD) methodology applied to the alpha of both regression models. The results reveal that most of the FoHFs fail to channel alpha from single-manager hedge funds and that only a small fraction of FoHFs delivers alpha per se. As a further confirmation, we also construct artificial FoHFs by randomly selecting hedge funds and comparing the performance of these artificial FoHFs to our sample of real FoHFs. The experiment shows that there is no meaningful difference between the performance of the real and artificial FoHFs.

\subsection{Alpha measurement}

The results presented in Tables 4 and 5 below are obtained by regressing the excess monthly returns of FoHFs having at least 60 months of returns during the period from January 1994 to August 2009 (i.e. 280 FoHFs) using the $16 \mathrm{~F}$ and DJCS model, respectively. The $t$ statistics and $p$-values are heteroskedasticity and autocorrelation consistent (HAC - QS). Columns 5 to 7 give the percentage of FoHFs having $p$-values smaller than 5,10 and 20\%, and columns 8-10 and 11-13 give the percentage of FoHFs with negative and positive alpha respectively and $p$-values smaller than 5,10 and $20 \%$. Using the $16 \mathrm{~F}$ model, we observe that at the $10 \%$ confidence level, $25 \%$ of FoHFs exhibit significant alpha, of which $3.57 \%$ exhibit significantly negative and $21.43 \%$ exhibit significantly positive alpha. The DJCS model, on the other hand, indicates that at the 10\% confidence level, $28.93 \%$ of FoHFs exhibit significantly negative alpha and only $6.79 \%$ exhibit significantly positive alpha. At every confidence level, the $16 \mathrm{~F}$ model shows a larger proportion of FoHFs with a positive alpha compared to the proportion of those with negative alpha. On the other hand, at every confidence level the DJCS model shows a larger proportion of FoHFs with negative alpha compared to the proportion of those with positive alpha.

In confirmation of the abovementioned pattern, comparing tables 4 and 5, we notice that the average alpha detected with the $16 \mathrm{~F}$ model is positive, while the one detected with the DJCS model is negative. Since the DJCS model compares the performance of FoHFs to hedge fund indices, this result may be seen as a confirmation of the results of Fung and Hsieh (2004) and Capocci et al. (2005) who find that FoHFs exhibit lower levels of alpha compared to single-manager hedge funds.

Table 4 reveals that large fractions of the FoHFs have statistically significant exposures to the Russell 3000 Index (RUSS3000-LIB), the MSCI World ex-US Index (MSCIWEUS-LIB), the momentum factor (MOM) and the Citigroup World Government Bond Index (CWGBILIB). Table 5 reveals that when benchmarked against the hedge fund indices, the proportions of FoHFs with statistically significant allocations to the various strategies are more comparable. Still, there are somewhat larger fractions of FoHFs with allocations to Dedicated Short Bias (DJCSDSB), Managed Futures (DJCSMF) and Long-Short Equity Hedge (DJCSLSEH). 
The tables also reveal that the DJCS model has a better explanatory power as far as FoHFs are concerned. This is evidenced by its average adjusted $R^{2}$ of $66.45 \%$ compared to $52.00 \%$ for the $16 \mathrm{~F}$ model. Nevertheless, the fact that FoHF returns are better explained by hedge fund indices' returns rather than by asset-based style factors' returns should not be a surprise. As far as explanatory power is concerned, it is also interesting to note that the original 10-factor model of Capocci et al. (2005) has a much higher explanatory power when applied to their sample of FoHFs than when applied to ours. Capocci et al. (2005) apply their model to a sample of 2'894 hedge funds and FoHFs for the sample period from 1994 to 2002. The adjusted $R^{2}$ for the sample of 647 FoHFs over their whole sample period is $70.1 \%$. Testing their model on our sample of FoHFs, however, produces an adjusted $R^{2}$ of only $49.41 \%$. 
Table 4

Regression Statistics for the 16-factor model

This table shows the regression statistics for our 16-factor regression model with factors coming from Fung and Hsieh (2004) and Capocci et al (2005). The regression has been applied to all FoHFs with at least 60 months of returns. $t$-stats and p-values are HAC-QS consistent.

\begin{tabular}{|c|c|c|c|c|c|c|c|c|c|c|c|c|}
\hline \multicolumn{4}{|l|}{ Number of funds: 280} & \multicolumn{3}{|c|}{ All alpha } & \multicolumn{3}{|c|}{ Negative Alpha } & \multicolumn{3}{|c|}{ Positive Alpha } \\
\hline Factor & $\begin{array}{l}\begin{array}{l}\text { Coefficient } \\
\text { (mean value) }\end{array} \\
\end{array}$ & $\begin{array}{l}t \text {-stat } \\
\text { (mean) }\end{array}$ & $\begin{array}{l}\text { p-value } \\
\text { (mean) }\end{array}$ & $\begin{array}{l}\% \text { funds } \\
\text { with p- } \\
\text { value < } \\
5 \%\end{array}$ & $\begin{array}{l}\% \text { funds } \\
\text { with } p- \\
\text { value }< \\
10 \%\end{array}$ & $\begin{array}{l}\% \text { funds } \\
\text { with p- } \\
\text { value < } \\
20 \%\end{array}$ & $\begin{array}{l}\% \text { funds } \\
\text { with p- } \\
\text { value < } \\
5 \% \\
\end{array}$ & $\begin{array}{l}\% \text { funds } \\
\text { with } p- \\
\text { value < } \\
10 \%\end{array}$ & $\begin{array}{l}\% \text { funds } \\
\text { with p- } \\
\text { value < } \\
20 \%\end{array}$ & $\begin{array}{l}\text { \% funds } \\
\text { with p- } \\
\text { value < } \\
5 \% \\
\end{array}$ & $\begin{array}{l}\% \text { funds } \\
\text { with p- } \\
\text { value < } \\
10 \%\end{array}$ & $\begin{array}{l}\% \text { funds } \\
\text { with p- } \\
\text { value < } \\
20 \% \\
\end{array}$ \\
\hline Constant & 0.001 & 0.678 & $40.76 \%$ & $18.57 \%$ & $25.00 \%$ & $36.07 \%$ & $1.43 \%$ & $3.57 \%$ & $8.21 \%$ & $17.14 \%$ & $21.43 \%$ & $27.86 \%$ \\
\hline D10Y & -1.190 & -0.712 & $39.93 \%$ & $14.64 \%$ & $24.29 \%$ & $32.86 \%$ & $13.21 \%$ & $21.43 \%$ & $27.86 \%$ & $1.43 \%$ & $2.86 \%$ & $5.00 \%$ \\
\hline DBAA-10Y & -0.955 & -0.534 & $42.25 \%$ & $12.14 \%$ & $18.57 \%$ & $31.43 \%$ & $10.71 \%$ & $15.71 \%$ & $25.00 \%$ & $1.43 \%$ & $2.86 \%$ & $6.43 \%$ \\
\hline PTFSBD & -0.009 & -0.737 & $35.26 \%$ & $13.93 \%$ & $26.07 \%$ & $39.64 \%$ & $11.79 \%$ & $22.14 \%$ & $33.57 \%$ & $2.14 \%$ & $3.93 \%$ & $6.07 \%$ \\
\hline PTFSFX & 0.011 & 1.131 & $34.47 \%$ & $21.07 \%$ & $27.50 \%$ & $42.86 \%$ & $0.36 \%$ & $0.36 \%$ & $1.07 \%$ & $20.71 \%$ & $27.14 \%$ & $41.79 \%$ \\
\hline PTFSCOM & -0.002 & -0.341 & $44.01 \%$ & $8.21 \%$ & $14.29 \%$ & $27.14 \%$ & $7.14 \%$ & $11.43 \%$ & $19.29 \%$ & $1.07 \%$ & $2.86 \%$ & $7.86 \%$ \\
\hline MSCIEM-LIB & 0.051 & 0.686 & $42.70 \%$ & $15.71 \%$ & $22.50 \%$ & $32.86 \%$ & $1.07 \%$ & $2.50 \%$ & $5.00 \%$ & $14.64 \%$ & $20.00 \%$ & $27.86 \%$ \\
\hline RUSS3000-LIB & -0.080 & -0.541 & $29.14 \%$ & $30.71 \%$ & $40.36 \%$ & $52.86 \%$ & $21.43 \%$ & $28.57 \%$ & $35.71 \%$ & $9.29 \%$ & $11.79 \%$ & $17.14 \%$ \\
\hline $\mathrm{SMB}$ & 0.048 & 0.809 & $41.26 \%$ & $16.43 \%$ & $23.21 \%$ & $35.71 \%$ & $1.43 \%$ & $1.79 \%$ & $4.29 \%$ & $15.00 \%$ & $21.43 \%$ & $31.43 \%$ \\
\hline HML & -0.051 & -0.574 & $35.45 \%$ & $18.93 \%$ & $26.43 \%$ & $39.29 \%$ & $13.21 \%$ & $18.57 \%$ & $28.57 \%$ & $5.71 \%$ & $7.86 \%$ & $10.71 \%$ \\
\hline MOM & 0.073 & 1.843 & $23.99 \%$ & $45.36 \%$ & $53.57 \%$ & $60.36 \%$ & $0.36 \%$ & $0.71 \%$ & $1.07 \%$ & $45.00 \%$ & $52.86 \%$ & $59.29 \%$ \\
\hline MSCIWEUS-LIB & 0.224 & 1.646 & $24.78 \%$ & $41.43 \%$ & $49.64 \%$ & $60.71 \%$ & $0.36 \%$ & $0.36 \%$ & $1.07 \%$ & $41.07 \%$ & $49.29 \%$ & $59.64 \%$ \\
\hline LHMGHY-LIB & 0.101 & 0.842 & $38.94 \%$ & $20.36 \%$ & $27.86 \%$ & $40.00 \%$ & $0.71 \%$ & $2.14 \%$ & $5.36 \%$ & $19.64 \%$ & $25.71 \%$ & $34.64 \%$ \\
\hline JPMEMBI-LIB & -0.062 & -0.523 & $44.65 \%$ & $12.14 \%$ & $15.36 \%$ & $28.93 \%$ & $11.07 \%$ & $12.86 \%$ & $24.64 \%$ & $1.07 \%$ & $2.50 \%$ & $4.29 \%$ \\
\hline GSCIC-LIB & 0.023 & 0.822 & $37.01 \%$ & $15.00 \%$ & $24.64 \%$ & $38.57 \%$ & $0.71 \%$ & $2.14 \%$ & $3.93 \%$ & $14.29 \%$ & $22.50 \%$ & $34.64 \%$ \\
\hline CWGBI-LIB & -0.153 & -1.199 & $29.98 \%$ & $25.71 \%$ & $37.86 \%$ & $51.79 \%$ & $25.00 \%$ & $36.07 \%$ & $48.21 \%$ & $0.71 \%$ & $1.79 \%$ & $3.57 \%$ \\
\hline \multirow{2}{*}{ MORTG-LIB } & -0.085 & -0.191 & $47.81 \%$ & $8.93 \%$ & $12.50 \%$ & $21.43 \%$ & $6.43 \%$ & $9.29 \%$ & $14.64 \%$ & $2.50 \%$ & $3.21 \%$ & $6.79 \%$ \\
\hline & Mean Value & $\begin{array}{c}\text { Min } \\
\text { Value }\end{array}$ & $\begin{array}{c}\text { Max } \\
\text { Value }\end{array}$ & & & & & & & & & \\
\hline R-Squared & $60.99 \%$ & $8.39 \%$ & $90.91 \%$ & & & & & & & & & \\
\hline Adjusted R-Squared & $52.00 \%$ & $-21.52 \%$ & $87.60 \%$ & & & & & & & & & \\
\hline Mean MSE & $0.05 \%$ & & & & & & & & & & & \\
\hline
\end{tabular}


Table 5

Regression Statistics for DJCS factors model

This table shows the regression statistics for the 13 -factor DJCS hedge fund indices model. The regression has been applied to all FoHFs with at least 60 months of returns. $t$-stats and p-values are HAC-QS consistent.

\begin{tabular}{|c|c|c|c|c|c|c|c|c|c|c|c|c|}
\hline \multicolumn{4}{|l|}{ Number of funds: 280} & \multicolumn{3}{|c|}{ All alpha } & \multicolumn{3}{|c|}{ Negative Alpha } & \multicolumn{3}{|c|}{ Positive Alpha } \\
\hline Factor & $\begin{array}{l}\text { Coefficient } \\
\text { (mean value) }\end{array}$ & $\begin{array}{l}t \text {-stat } \\
\text { (mean) }\end{array}$ & $\begin{array}{l}\mathrm{p} \text {-value } \\
\text { (mean) }\end{array}$ & $\begin{array}{l}\% \text { funds } \\
\text { with p- } \\
\text { value < } \\
5 \%\end{array}$ & $\begin{array}{l}\% \text { funds } \\
\text { with } p- \\
\text { value < } \\
10 \%\end{array}$ & $\begin{array}{l}\% \text { funds } \\
\text { with p- } \\
\text { value < } \\
20 \%\end{array}$ & $\begin{array}{l}\% \text { funds } \\
\text { with p- } \\
\text { value < } \\
5 \% \\
\end{array}$ & $\begin{array}{l}\% \text { funds } \\
\text { with } p- \\
\text { value }< \\
10 \%\end{array}$ & $\begin{array}{l}\% \text { funds } \\
\text { with p- } \\
\text { value < } \\
20 \%\end{array}$ & $\begin{array}{l}\% \text { funds } \\
\text { with p- } \\
\text { value < } \\
5 \% \\
\end{array}$ & $\begin{array}{l}\% \text { funds } \\
\text { with p- } \\
\text { value < } \\
10 \%\end{array}$ & $\begin{array}{l}\% \text { funds } \\
\text { with p- } \\
\text { value < } \\
20 \% \\
\end{array}$ \\
\hline Constant & -0.002 & -0.894 & $30.48 \%$ & $29.29 \%$ & $35.71 \%$ & $51.07 \%$ & $24.64 \%$ & $28.93 \%$ & $40.00 \%$ & $4.64 \%$ & $6.79 \%$ & $11.07 \%$ \\
\hline DJCSCA & -0.044 & -0.070 & $38.02 \%$ & $16.79 \%$ & $24.64 \%$ & $36.79 \%$ & $8.93 \%$ & $13.21 \%$ & $19.64 \%$ & $7.86 \%$ & $11.43 \%$ & $17.14 \%$ \\
\hline DJCSDSB & 0.005 & 0.083 & $37.49 \%$ & $19.64 \%$ & $27.86 \%$ & $38.93 \%$ & $8.57 \%$ & $13.21 \%$ & $17.86 \%$ & $11.07 \%$ & $14.64 \%$ & $21.07 \%$ \\
\hline DJCSHD & -0.110 & -0.383 & $40.72 \%$ & $15.71 \%$ & $21.43 \%$ & $32.50 \%$ & $10.00 \%$ & $13.93 \%$ & $22.86 \%$ & $5.71 \%$ & $7.50 \%$ & $9.64 \%$ \\
\hline DJCSEMN & 0.029 & -0.090 & $36.09 \%$ & $15.71 \%$ & $24.29 \%$ & $42.14 \%$ & $7.86 \%$ & $13.21 \%$ & $23.57 \%$ & $7.86 \%$ & $11.07 \%$ & $18.57 \%$ \\
\hline DJCSED & 0.132 & 0.547 & $41.62 \%$ & $16.79 \%$ & $21.79 \%$ & $35.36 \%$ & $1.43 \%$ & $3.21 \%$ & $8.93 \%$ & $15.36 \%$ & $18.57 \%$ & $26.43 \%$ \\
\hline DJCSFIA & -0.011 & -0.014 & $39.99 \%$ & $14.64 \%$ & $22.14 \%$ & $31.79 \%$ & $6.79 \%$ & $10.36 \%$ & $15.71 \%$ & $7.86 \%$ & $11.79 \%$ & $16.07 \%$ \\
\hline DJCSMF & 0.016 & 0.203 & $36.89 \%$ & $22.50 \%$ & $26.79 \%$ & $42.86 \%$ & $8.93 \%$ & $12.14 \%$ & $21.07 \%$ & $13.57 \%$ & $14.64 \%$ & $21.79 \%$ \\
\hline DJCSRA & -0.097 & -0.379 & $41.13 \%$ & $13.21 \%$ & $22.86 \%$ & $33.93 \%$ & $8.21 \%$ & $16.07 \%$ & $23.21 \%$ & $5.00 \%$ & $6.79 \%$ & $10.71 \%$ \\
\hline DJCSEM & 0.034 & 0.286 & $39.39 \%$ & $15.36 \%$ & $22.50 \%$ & $33.93 \%$ & $5.00 \%$ & $7.14 \%$ & $13.21 \%$ & $10.36 \%$ & $15.36 \%$ & $20.71 \%$ \\
\hline DJCSGM & -0.070 & -0.118 & $39.69 \%$ & $12.14 \%$ & $22.50 \%$ & $34.64 \%$ & $6.43 \%$ & $13.57 \%$ & $21.07 \%$ & $5.71 \%$ & $8.93 \%$ & $13.57 \%$ \\
\hline DJCSLSEH & 0.049 & 0.363 & $37.95 \%$ & $18.21 \%$ & $28.57 \%$ & $37.14 \%$ & $3.57 \%$ & $9.29 \%$ & $13.93 \%$ & $14.64 \%$ & $19.29 \%$ & $23.21 \%$ \\
\hline DJCSMS & 0.114 & 0.507 & $39.91 \%$ & $15.00 \%$ & $24.64 \%$ & $36.43 \%$ & $3.57 \%$ & $5.00 \%$ & $8.93 \%$ & $11.43 \%$ & $19.64 \%$ & $27.50 \%$ \\
\hline DJCSHF & 0.865 & 0.458 & $39.25 \%$ & $16.07 \%$ & $26.43 \%$ & $36.43 \%$ & $4.64 \%$ & $7.14 \%$ & $10.36 \%$ & $11.43 \%$ & $19.29 \%$ & $26.07 \%$ \\
\hline & Mean Value & $\begin{array}{c}\text { Min } \\
\text { Value }\end{array}$ & $\begin{array}{c}\text { Max } \\
\text { Value } \\
\end{array}$ & & & & & & & & & \\
\hline R-Squared & $71.54 \%$ & $5.42 \%$ & $96.91 \%$ & & & & & & & & & \\
\hline Adjusted R-Squared & $66.45 \%$ & $-18.23 \%$ & $96.15 \%$ & & & & & & & & & \\
\hline Mean MSE & $0.04 \%$ & & & & & & & & & & & \\
\hline
\end{tabular}




\subsection{False discoveries}

As already explained in section 4, we apply the FD procedure to the alphas detected with the $16 \mathrm{~F}$ and DJCS model. In addition to controlling for luck in the alphas, the FD procedure also frees us from having to choose a suitable confidence level, which we had to do in Tables 4 and 5. Looking at Panel A of table 6 below, we see that approximately $79 \%$ of FoHFs failed to channel alpha from single-manager hedge funds (remember that we study net-of-fees returns), approximately $21 \%$ channelled positive alpha and $0 \%$ channelled negative alpha. Therefore, when regressed on hedge fund asset-based style factors, approximately one in five FoHFs exhibits alpha-channelling skills.

Table 6

Results of False Discoveries Procedure

This table shows the partition of FoHFs into zero-alpha, skilled and unskilled when the FD procedure is applied to the alpha detected by (Panel A) the 16-factor model and (Panel B) the DJCS model.

Panel A

\begin{tabular}{cccc}
\hline 16F Model & Zero-Alpha Funds & Skilled Funds & Unskilled Funds \\
\hline \% & 78,83 & 21,17 & 0 \\
Standard Deviation & $4,24 \%$ & $3,95 \%$ & $1,12 \%$ \\
\hline
\end{tabular}

Panel B

\begin{tabular}{cccc}
\hline DJCS Model & Zero-Alpha Funds & Skilled Funds & Unskilled Funds \\
\hline$\%$ & 46,94 & 5,56 & 47,50 \\
Standard Deviation & $6,33 \%$ & $2,17 \%$ & $5,56 \%$ \\
\hline
\end{tabular}

Panel B of table 6, however, shows a different picture. Since the DJCS model compares the performance of our sample of FoHFs to hedge fund indices, it would allow us to observe whether FoHFs can deliver any after-fees alpha above that already delivered by the individual hedge funds that constitute these indices. We would expect an investment into a FoHF to bring benefits from diversification with the FoHF at the same time selecting the best-performing single-manager hedge funds from the best-performing strategies (i.e. hedge funds with positive alpha). Panel B of table 6, however, shows that FoHFs failed to outperform the hedge fund indices (from a net-of-fees point of view). After management and incentive fees, the performance of FoHFs is worse than what we would have expected. Indeed, only $5.56 \%$ of FoHFs managed to provide after-fees alpha, and $47.5 \%$ delivered negative alpha.

We also decided to assess our sample of FoHFs by regressing their performance on investable hedge fund indices. For this purpose we used 11 Dow Jones Credit Suisse bluechip factors. The period for which these bluechip factors are available, however, only starts in August 2003. The results when the FD procedure is applied to the alpha detected using he bluechip indices are slightly more favourable for FoHFs but they still show that only a very small fraction of FoHFs delivers alpha per se. For a sample period from August 2003 to August 2009, using the bluechip model produces 8.86\% of skilled FoHFs while using the DJCS model produces 0\% of skilled funds. Detailed results are available in Appendix 1. 


\subsection{The original Fung and Hsieh, and Capocci, Corhay and Hübner factors}

Since our 16F model is an extension of the models proposed by Fung and Hsieh (2004) and Capocci et al. (2005), we present here a comparison of the results produced by the $16 \mathrm{~F}$ model and the results produced by the original models of Fung and Hsieh (2004) and Capocci et al (2005). Fung and Hsieh (2004) have shown that their original 7 -factor model does have significant explanatory power for FoHF and hedge fund returns. In this paper, we test an 8factor model composed of the original 7 factors of Fung and Hsieh (2004) and the emerging markets factor as later suggested by the authors themselves. (The emerging markets factor is included in our $16 \mathrm{~F}$ model as well.)

The set of factors of the Fung and Hsieh (2004) model that we test thus consists of the monthly change in the difference between the 10-year Treasury constant maturity yield and the 1-month LIBOR (month end-to-month end) (D10Y-LIB), the change in the credit spread of Moody's BAA bond over the 10-year Treasury bond (DBAA-10Y), the excess return on the S\&P 500 Index (SNP-LIB), the difference between the Russell 2000 Index' monthly returns and the S\&P 500 Index' monthly returns (RUL-SP500), the excess returns on a portfolio of lookback options ${ }^{1}$ on bonds (PTFSBD), currencies (PTFSFX), and commodities (PTFSCOM) and, as suggested by David Hsieh on his webpage, the excess return on the MSCI Emerging Markets Index (MSCIEM-LIB) ${ }^{2}$.

The original 10-factor model of Capocci et al. (2005) also has significant explanatory power when it comes to the performance of FoHFs and hedge funds. It had the highest adjusted $R^{2}$ reported in the literature to date. The set of factors of their model consists of the excess return on the Russell 3000 Index (RUSS3000-LIB), a small-minus-big factor (SMB), a high-minus-low factor (HML), a momentum factor (MOM) ${ }^{3}$, the excess return on the MSCI World ex-US Index (MSCIWEUS-LIB), the excess return on the Barclays Macro Global High Yield Index (LHMGHY-LIB), the excess return on the J.P. Morgan Emerging Markets Bond Index Global Composite (JPMEMBI-LIB), the excess return on the S\&P GSCI Commodity Index (GSCIC-LIB), the excess return on the Citigroup World Government Bond Index (CWGBI-LIB), and the excess return on Lehman Mortgage-Backed Securities Index (MORTG-LIB).

The above two regressions are performed on the excess monthly returns of the same sample of FoHFs for the same period as our $16 \mathrm{~F}$ regression, i.e. all FoHFs with at least 60 months of returns for the period from January 1994 to August 2009. Table 7 below compares the partition among zero-alpha, skilled and unskilled funds when the FD methodology is applied to the alpha detected by the $16 \mathrm{~F}$ model and the original models of Fung and Hsieh (2004) and Capocci et al. (2005). The reader is reminded that the results of all three models below present the skills of FoHFs managers of channelling alpha from single-manager hedge funds.

\footnotetext{
${ }^{1}$ More information about the excess return on the lookback options can be found in Fung \& Hsieh (2001).

2 The non-linear factors come from David Hsieh's website: http://faculty.fuqua.duke.edu/ dah7/HFRFData.htm

3 Downloaded from Kenneth French's website.
} 
Table 7

Comparison of 16-factor, FH and CCH models

This table shows the partition among zero-alpha, skilled and unskilled FoHFs when the FD procedure is applied to three regression modes - (Panel A) our $16 \mathrm{~F}$ model, (Panel B) the 8-factor Fung and Hsieh model and (Panel C) the 10-factor Capocci, Corhay and Hübner model

Panel A

\begin{tabular}{cccc}
\hline 16F Model & Zero-Alpha Funds & Skilled Funds & Unskilled Funds \\
\hline$\%$ & 78,83 & 21,17 & 0,00 \\
Standard Deviation & $4,24 \%$ & $3,95 \%$ & $1,12 \%$ \\
\hline
\end{tabular}

Panel B (highlighted by Hugues)

\begin{tabular}{lccc}
\hline FH & Zero-Alpha Funds & Skilled Funds & Unskilled Funds \\
\hline$\%$ & 76,37 & 7,13 & 16,5 \\
Standard Deviation & $4,60 \%$ & $2,16 \%$ & $3,95 \%$ \\
\hline
\end{tabular}

Panel C (highlighted by Hugues)

\begin{tabular}{lccc}
\hline CCH & Zero-Alpha Funds & Skilled Funds & Unskilled Funds \\
\hline$\%$ & 65,83 & 34,17 & 0 \\
Standard Deviation & $6,09 \%$ & $5,76 \%$ & $1,01 \%$ \\
\hline
\end{tabular}

As the table shows, the Capocci et al. (2005) model produces a much larger proportion of skilled funds compared to the Fung and Hsieh (2004) model and a smaller proportion of both zero-alpha and unskilled funds. Similar to our $16 \mathrm{~F}$ model, the Capocci et al. (2005) model in fact produces no unskilled funds. Moreover, we observe that the $16 \mathrm{~F}$ model yields a partition which is more similar to the one of the Capocci et al. (2005) model than the one of the Fung and Hsieh (2004) model. The reason for this is that we use more factors from Capocci et al. (2005) compared to Fung and Hsieh (2004). Yet, the FD procedure, when applied with our $16 \mathrm{~F}$ model, gives a smaller proportion of skilled funds and a larger proportion of zero-alpha funds compared to the proportions resulting from Capocci et al. (2005). It is also interesting to mention here that the small proportion of skilled FoHFs obtained using the Fung and Hsieh (2004) regression is still larger than the proportion of skilled FoHFs obtained using the DJCS regression. For detailed results on the regression statistics of the two models, refer to Appendix 3.

\subsection{Real vs. artificial FoHFs}

The results of the FD procedure tell us that as a group, FoHFs do not channel after-fees alpha from single-manager hedge funds. This, however, does not necessarily mean that they do not possess hedge fund picking skills or strategy timing. It could mean that any added value from the latter is offset by the fees FoHFs charge. To check whether FoHFs possess fund picking and timing skills we conducted a bootstrap experiment designed to assess whether real FoHFs manage to outperform artificial FoHFs constructed by randomly picking hedge funds. As explained in section 4.3, we constructed 1'315 artificial FoHF returns, and the returns of this sample of FoHFs are then averaged on an equally-weighted basis to determine the monthly returns of a portfolio of FoHFs. Table 8 summarizes the mean monthly returns of the portfolios of 1'315 real and 1'315 bootstrapped FoHFs for 
different rebalancing periods for the period January 1995 - August 2009. The standard deviation of the means is obtained by generating 1'000 samples of 1'315 artificial FoHFs. The p-values correspond to the $\mathrm{p}$-value of the test:

$$
\begin{aligned}
& H_{0}: \mu_{\text {Bootstrap }}=\mu_{\text {Real }} \\
& H_{1}: \mu_{\text {Bootstrap }} \leq \mu_{\text {Real }}
\end{aligned}
$$

Where $\mu_{\text {Real }}$ denotes the mean monthly return of the portfolio of real FoHFs, and $\mu_{\text {Bootstrap }}$ the mean monthly return of the portfolio of bootstrapped FoHFs.

Table 8

Performance of randomly generated FoHFs

This table compares the mean monthly performance over the period 1/1995 - 8/2009 of an equally-weighted portfolio of 1'315 real FoHFs and an equally-weighted portfolio of 1'315 artificial FoHFs when different rebalancing periods are applied. The monthly returns of the portfolios of FoHFs are computed as the weighted average of all the FoHFs available during the month. The returns of the underlying FoHFs are computed as detailed in section 4.3. The mean value and standard deviation are computed by generating 1'000 samples of 1315 artificial HFs and computing the mean monthly performance of the equally-weighted portfolio. The $\mathrm{p}$ -

value corresponds to the $\mathrm{p}$-value of the test detailed in section 5.4, and is computed using the bootstrap previously detailed.

\begin{tabular}{cccc} 
Re-balancing Period & Mean Value & Standard Deviation & p-value \\
\hline Real Sample & $0,44460 \%$ & - & - \\
6 Months & $0,44219 \%$ & $0,00992 \%$ & $59,90 \%$ \\
12 Months & $0,45526 \%$ & $0,01027 \%$ & $13,40 \%$ \\
18 Months & $0,45163 \%$ & $0,01047 \%$ & $25,80 \%$ \\
24 Months & $0,45211 \%$ & $0,01089 \%$ & $24,20 \%$ \\
30 Months & $0,44907 \%$ & $0,01135 \%$ & $34,50 \%$ \\
36 Months & $0,44024 \%$ & $0,01084 \%$ & $65,80 \%$ \\
\hline
\end{tabular}

Table 8 seriously questions the managers' ability to deliver after-fees performance that is significantly different from the one obtained by random hedge fund picking. Table 9 compares the characteristics of the monthly performance of the portfolio of real FoHFs and the portfolio of artificial FoHFs for a re-balancing period of 12 months.

In figure 1, we draw a histogram of the mean monthly performances (over the period 1/1995-8/2009) of one of the thousand exercises presented above. It shows the distribution of the equally-weighted monthly returns of the portfolios of 1'315 real and simulated FoHFs each. The construction of the 1'315 underlying FoHFs is explained in section 4.3. The graph depicts an interesting pattern, the distributions' shapes are similar but compared to the sample of real FoHFs, the mean returns of artificial FoHFs are more concentrated around the mean of 0 to $1 \%$, in terms of number of months showing similar results. Moreover, the real distribution apparently shows fatter tails on the left-hand side of the distribution due to a skew on the right-hand side. That shows that the overall risk exposure may be different even though mean differences would not be significant. 
Table 9

Performance comparison of the portfolios of real and randomly generated FoHFs

This table shows the performance characteristics of the portfolios of real FoHFs and artificial FoHFs. The standard deviation is obtained by generating a sample of 1'000 artificial portfolios of FoHFs. The rebalancing period of the underlying FoHFs is 12 months.

\begin{tabular}{cccc} 
& Real & Bootstrap & Standard Deviation \\
\hline Mean & $0,44460 \%$ & $0,45526 \%$ & $0,01027 \%$ \\
Standard Deviation & $1,77562 \%$ & $1,99720 \%$ & $0,01842 \%$ \\
Median & $0,59164 \%$ & $0,69814 \%$ & $0,03916 \%$ \\
Minimum & $-6,33782 \%$ & $-6,73517 \%$ & $0,30980 \%$ \\
Maximum & $6,35408 \%$ & $6,83113 \%$ & $0,22271 \%$ \\
\hline
\end{tabular}

Figure 1 - Monthly time-series distribution of returns of real and simulated FoHFs (1/1995-8/2009). 1315 drawings of 15 hedge funds (among those available) are performed to produce a sample of 1'315 simulated FoHFs to be compared to the sample of 1'315 real FoHFs. Periods of existence and fees are perfectly matched with those of the real FoHFs. The 1'315 funds of each sample are then equally-weighted into a portfolio. For each month, a mean return is thus available for both portfolios. The figure shows the distribution of monthly mean returns for both portfolios, i.e. the percentage of months for a given return bucket. The present figure shows the exercise with a 12-month reallocation frequency (the random choice is performed at the beginning and then every year for the same period of existence as for the real FoHF, with a verification still for the hedge fund that would have been liquidated in the meantime).

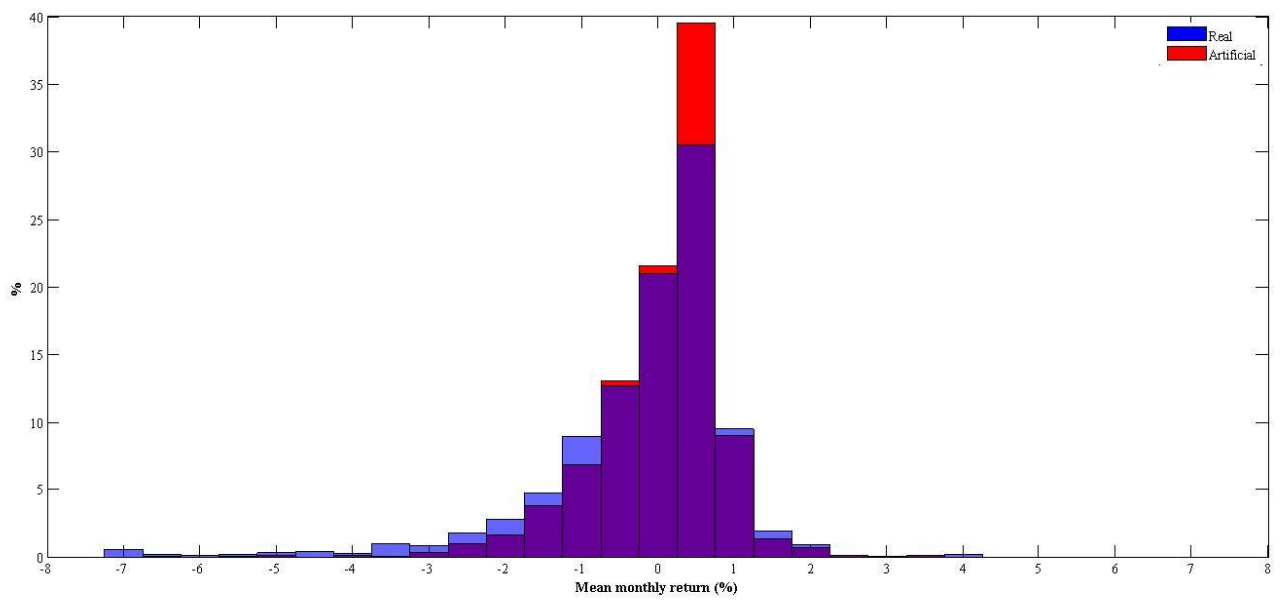

Figure 2 compares cross-sectionally the overall average return performance (over the period 1/1995-8/2009) directly on the 1'315 real and the 1'315 simulated FoHFs. We can observe that artificial FoHFs have a higher frequency of extreme returns compared to that of real FoHFs. The distribution of the returns of the artificial portfolio also appears to be less peaked than that of the real portfolio. This figure complements the previous one since it presents a cross-sectional view of the results. The wider dispersion of artificial FoHFs may nevertheless be due to the fact that the randomization gives the same priority to funds with a very short existence than to others. And the averaging over small periods for some of them creates more outliers than what the practice - of investing in funds with a sufficient trackrecord - would suggest. 
Figure 2 - Cross-sectional distribution of mean returns of real and simulated FoHFs (1/1995-8/2009). 1315 drawings of 15 hedge funds (among those available) are performed to produce a sample of 1'315 simulated FoHFs to be compared to the sample of 1'315 real FoHFs. Periods of existence and fees are perfectly matched with those of the real FoHFs. The figure presents the distribution of mean returns over the entire corresponding period for each FoHF (with varying lifetimes), either simulated or real. It is the direct distribution of FoHFs' returns, without any averaging into a portfolio as in Figure 1 . The present figure shows the exercise with a 12 -month reallocation frequency (the random choice is performed at the beginning and then every year for the same period of existence as for the real hedge fund, with a verification still for the hedge fund that would have been liquidated in the meantime). Returns are computed on a monthly basis. Extreme mean returns are mostly generated for FoHF with a very short existence, reduced by the mentioned corrections of selection biases.

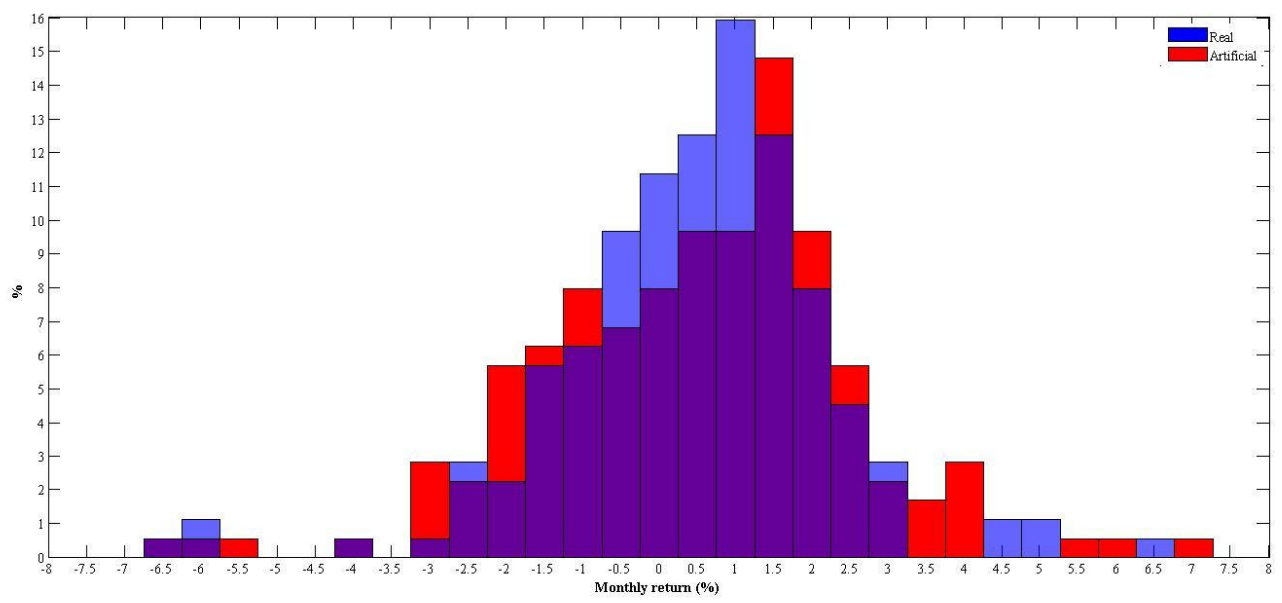

\subsection{Conclusion}

Applying the FD procedure to the alpha detected by the $16 \mathrm{~F}$ and DJCS models suggests that for the most part FoHFs do not provide alpha. We ground this conclusion on our use of two regression models to detect the alpha. The $16 \mathrm{~F}$ model allows us to detect the alphachannelling skills of FoHFs using traditional hedge fund asset-based style factors and the DJCS model allows us to benchmark FoHFs against the performance of hedge fund indices. We have thus seen that approximately $21 \%$ of FoHFs show alpha-channelling skills, but only slightly more than 5\% of FoHFs seem to deliver any additional after-fees alpha on top of that already delivered by the universe of single-manager hedge funds.

Our findings, therefore, show that in general FoHFs do not exhibit alpha delivering skills. On the contrary, a large proportion of them exhibit negative alpha when benchmarked against hedge fund indices. The results of the FD procedure tell us that after fees any pre-existing hedge fund picking skills are lost. The results of the comparison between real and artificial FoHFs would moreover suggest that such hedge fund picking skills are on average close to non-existent in the first place.

\section{Sensitivity analysis and robustness checks}

As already explained, the above analysis on the performance of FoHFs is based on FoHFs having at least 60 months of returns. This amount is justified by the fact that the number of regressors is large and by the fact that increasing this requirement will diminish the database and make the false discoveries (FD) procedure less precise. However, as stated by 
Kosowski et al. (2006), it is possible that this minimum requirement may impose survivorship bias on our results. We decided to run the same computations for FoHFs having at least 36 months of returns. ${ }^{4}$ Changing the minimum requirement does not qualitatively change our results but the distribution of zero-unskilled-skilled alphas is shifted towards the unskilled funds. Evidence suggests that this is simply the effect of the survivorship bias.

In order to verify the results of the FD procedure, we also performed a series of robustness checks presented below. All of the robustness checks were conducted on our original sample of FoHFs having at least 60 months of returns. The results below give us confidence in the validity of the results obtained using the FD procedure.

\subsection{Time series dependence}

Using our bootstrap procedure, we assumed that there is no autocorrelation or heteroskedasticity in our residuals. As stated by Kosowski et al. (2006), this is a strong assumption (although dependences in return can be generated through factor dependencies). The Engle and Ljung-Box tests show that for some FoHFs the assumptions of ARCH effects and heteroskedasticity cannot be rejected. Therefore we decided to check whether time dependence in the residuals and factors can be an issue by using 3 different bootstrap procedures. The first one is suggested by Kosowski et al. (2006) and try to model the dependence in the residuals using the block bootstrap of Politis and Romano ${ }^{5}$. We used blocks of residuals generated by a geometric distribution with a parameter going from 0.1 to 0.35 . The results of this bootstrap are very similar to our original results and are detailed in Table 10.

Table 10

Results of False Discoveries Procedure using the block bootstrap procedure for the residuals

This table shows the partition among zero-alpha, skilled and unskilled funds using the Politis and Romano block bootstrap procedure for residuals. Panel A shows the FD procedure applied to the alpha of the 16-factor model and Panel B shows the FD procedure applied to the alpha of the DJCS model.

Panel A

\begin{tabular}{cccc}
\hline 16F Model & Zero-Alpha Funds & Skilled Funds & Unskilled Funds \\
\hline \% & 76,40 & 23,60 & 0 \\
Standard Deviation & $4,26 \%$ & $3,97 \%$ & $1,12 \%$ \\
\hline
\end{tabular}

Panel B

\begin{tabular}{cccc}
\hline DJCS Model & Zero-Alpha Funds & Skilled Funds & Unskilled Funds \\
\hline$\%$ & 46,42 & 5,63 & 47,95 \\
Standard Deviation & $6,90 \%$ & $2,20 \%$ & $6,06 \%$ \\
\hline
\end{tabular}

The second procedure is also suggested by Kosowski et al. (2006) and uses the same bootstrap procedure we use in sections 5.2 and 5.3 for the residuals and for the factors. This

\footnotetext{
${ }^{4}$ The reduction to 36 months of returns added 208 additional funds to our database.

${ }^{5}$ We did this for an average block size going from 2 to 7 .
} 
bootstrap allows to check if the initial time ordering of the factors can be of any importance. The results are presented in Table 11.

Table 11

Results of False Discoveries Procedure using the bootstrap procedure of BSW for factors and residuals

This table shows the partition among zero-alpha, skilled and unskilled funds using the bootstrap procedure we use in sections 5.2 and 5.3 for the factors and for the residuals. Panel A shows the FD procedure applied to the alpha of the 16-factor model and Panel B shows the FD procedure applied to the alpha of the DJCS model.

Panel A

\begin{tabular}{cccc}
\hline 16F Model & Zero-Alpha Funds & Skilled Funds & Unskilled Funds \\
\hline \% & 79,34 & 20,66 & 0 \\
Standard Deviation & $4,24 \%$ & $3,78 \%$ & $1,51 \%$ \\
\hline
\end{tabular}

Panel B

\begin{tabular}{cccc}
\hline DJCS Model & Zero-Alpha Funds & Skilled Funds & Unskilled Funds \\
\hline$\%$ & 47,96 & 5,43 & 46.61 \\
Standard Deviation & $6,38 \%$ & $2,18 \%$ & $5,60 \%$ \\
\hline
\end{tabular}

In order to check if time series dependences in factors and residuals can have an impact, we also performed a bootstrap using the procedure of Politis and Romano both for residuals and factors. The results of this bootstrap are presented in table 12 below. Table 12 shows that the results produced by the block bootstrap procedure for factors and residuals are very similar to the results already presented in table 6 , section 5.2.

Table 12

False Discoveries using the Politis and Romano Procedure

This table shows the partition among zero-alpha, skilled and unskilled funds using the Politis and Romano block bootstrap procedure for factors and residuals. Panel A shows the FD procedure applied to the alpha of 16 -factor model and Panel B shows the FD procedure applied to the alpha of the DJCS model.

Panel A

\begin{tabular}{cccc}
\hline 16F Model & Zero-Alpha Funds & Skilled Funds & Unskilled Funds \\
\hline$\%$ & 76,53 & 23,47 & 0,00 \\
Standard Deviation & $4,25 \%$ & $3,98 \%$ & $1,06 \%$ \\
\hline
\end{tabular}

Panel B

\begin{tabular}{cccc}
\hline DJCS Model & Zero-Alpha Funds & Skilled Funds & Unskilled Funds \\
\hline$\%$ & 48,81 & 5,33 & 45,86 \\
Standard Deviation & $7,04 \%$ & $2,21 \%$ & $6,17 \%$ \\
\hline
\end{tabular}

For the $16 \mathrm{~F}$ model, our original FD procedure yields a proportion of zero-alpha funds equal to $78.83 \%$ and a proportion of skilled funds equal to $21.17 \%$. The differences therefore are very small compared to the results in table 12. Regarding the DJCS model, the original 
FD procedure produces $46.94 \%$ of zero-alpha funds, $5.56 \%$ or skilled funds and $47.50 \%$ of unskilled funds. The changes in both cases, therefore, are too small to constitute any significant qualitative difference. Overall, we see that the results of this bootstrap confirm our previous results that the majority of FoHFs do not exhibit alpha, especially when we account for the alpha already delivered by single-manager hedge funds.

\subsection{False discoveries on additional simulations}

In order to check if heteroskedasticity and autocorrelation can have an impact on our results via a bad estimation of the $t$-statistics, we decided to apply the following methodology. We first regress our initial FoHFs on our factors to obtain the betas associated with these factors and the residuals associated with our regression. We then fit an ARMA process without mean with GARCH innovations on the residuals. To obtain the new vector of FoHF returns, we multiply the betas by their associated factors, add residuals simulated using a GARCH $(1,1)$ process and regress the vector on the factors. For both the $16 \mathrm{~F}$ and the DJCS model, the bootstrap procedure leads to a zero-alpha fund proportion of $100 \%$. Table 13 below presents the results.

Table 13

Results of the FD procedure on ARMA-GARCH generated FoHFs

This table shows the results of the FD procedure on FoHFs constructed by multiplying the factors of the $16 \mathrm{~F}$ model by their coefficients and adding an ARMA process with $\operatorname{GARCH}(1,1)$ shocks to the residuals.

Panel A

\begin{tabular}{cccc}
\hline 16F Model & Zero-Alpha Funds & Skilled Funds & Unskilled Funds \\
\hline$\%$ & 99,16 & 0,00 & 0,84 \\
Standard Deviation & $3,93 \%$ & $1,34 \%$ & $3,51 \%$ \\
\hline
\end{tabular}

Panel B

\begin{tabular}{cccc}
\hline DJCS Model & Zero-Alpha Funds & Skilled Funds & Unskilled Funds \\
\hline$\%$ & 98,81 & 0,77 & 0,42 \\
Standard Deviation & $4,89 \%$ & $1,48 \%$ & $4,44 \%$ \\
\hline
\end{tabular}

As a further confirmation of the validity of our results, we also decided to build an artificial sample of FoHF performances using the same methodology we used in section 4.3. We constructed a sample of 1'000 FoHFs with the same properties as the initial portfolio (same starting dates, etc.) using 12 out of the 13 strategies we have in our sample of hedge funds (except the 'Undefined' strategy which represents a negligible part of our sample). The FoHF returns are computed as the average of the 15 randomly selected hedge funds (setting incentive and management fees to 0). We regressed those artificial FoHFs on 13 artificial index returns constructed as the mean of the returns of all strategies, the last index being the mean of all the hedge funds (again we did not compute an index for the 'Undefined' strategy). The results of the FD procedure are shown in table 14 below. The results in the table are to be expected as our randomly-constructed FoHFs cannot show alpha delivering skills in this setup. 
Table 14

Results of the FD procedure on randomly generated FoHFs

This table shows the results of the FD procedure on randomly generated FoHFs.

\begin{tabular}{cccc}
\hline & Zero-Alpha Funds & Skilled Funds & Unskilled Funds \\
\hline$\%$ & 99,29 & 0,51 & 0,20 \\
Standard Deviation & $2,42 \%$ & $0,87 \%$ & $2,15 \%$ \\
\hline
\end{tabular}

As already mentioned, the hypothesis of heteroskedasticity and autocorrelation cannot always be rejected which necessitated the use of HAC estimators. As the goal of the FD procedure is to detect skilled and unskilled funds which are not considered as such by luck alone, the results of the procedure on randomly generated FoHFs should give a proportion of about $100 \%$ of zero-alpha funds (as the FoHFs are randomly generated, skilled and unskilled funds should appear as such by luck alone). Using Newey-West always leads to proportion lower than 100\% (sometimes lower than 90\%). Among the sample of HAC estimators tested (Truncated, Tukey-Hanning, Bartlett and Parzen), the Newey-West estimators give the worst results whereas QS gives the best ones.

\subsection{Determination of the mean squared error of the percentage of zero- alpha funds}

In their FD procedure, Barras et al. (2010) determine the proportion of zero-alpha funds for lambdas going from $30 \%$ to $70 \%$ using the p-values bootstrap of step (c) of our methodology. They then select the lambda which will determine the proportion used by generating 1'000 samples of p-values (in our case 1'000 samples of $280 \mathrm{p}$-values) and using those samples to compute an MSE for each lambda. To compute the lambdas' MSE we compute the value of the proportion of zero-alpha FoHFs for lambdas going from $30 \%$ to $70 \%$ in each of our 1'000 samples of $280 \mathrm{p}$-values. We then compute an MSE for each lambda by computing the sum of the squared differences between the proportion of zero-alpha FoHFs in our sample and the minimum value of pi-zero determined initially (i.e. the pi-zero determined using the initial distribution of $\mathrm{p}$-value obtained in step (c)). As our number of FoHFs is small, the pizero distribution is not always smooth for all the lambdas between $30 \%$ and $70 \%$. We decided to check if selecting the mean of the pi-zero derived at the end of step (c) instead of the minimum value can have an impact on the choice of $\lambda^{*}$. The results we obtained with this bootstrap are very similar to our reported results and are available upon request.

\section{Conclusion}

In this paper we offered a comprehensive assessment of the performance of FoHFs. We started by constructing a 16-factor (16F) model based on factors chosen from Fung and Hsieh (2004) and Capocci et al. (2005), which proves to have good explanatory power. We also used a second model composed of 13 hedge fund indices provided by Dow Jones Credit Suisse. This second model (DJCS) allowed us to verify whether the alpha detected by the first model is a particularity of the underlying hedge funds or whether there is additional added value by FoHFs. 
Using the false discoveries (FD) technique of Barras et al. (2010), we were able to partition the sample of FoHFs into zero-alpha, skilled and unskilled funds. The results of the FD procedure show that the vast majority of FoHFs do not exhibit any alpha. The proportion of skilled funds obtained using the $16 \mathrm{~F}$ model is $21.17 \%$ while the proportion of skilled funds obtained using the DJCS model is a mere $5.56 \%$. The difference comes to show that when regressed on traditional hedge fund asset-based style factors, some FoHFs exhibit alpha-channelling skills. When regressed on hedge funds indices using the DJCS model, however, only a small fraction of FoHFs deliver alpha per se, i.e. above the one already delivered by the universe of single-manager hedge funds. This means that the additional layer of fees that FoHFs charge investors eats away any manager added value. The series of robustness checks gives us confidence in the results we have obtained. In addition, we showed that the average performance of our sample of FoHFs is almost the same as the one of the sample of artificial FoHFs constructed by randomly picking hedge funds. This result is a confirmation of the results already obtained by the FD procedure.

One result in favour of FoHFs is the slightly higher proportion of skilled funds obtained by regressing our sample of FoHFs on the investable DJCS Bluechip indices. This regression shifts a small proportion of funds to the skilled category. Nevertheless, the sample period of the regression on the DJCS Bluechip factors is relatively short and the proportion of $8.86 \%$ of skilled funds is relatively low to suggest any meaningful alpha per se on the part of the FoHF industry. The FoHF industry offers investors access to the hedge fund market by adding diversification. We would have expected FoHFs to deliver positive alpha to investors by investing in the best hedge funds and strategies at the right time. The small fraction of FoHFs that deliver alpha per se (5.56\%), however, shows that any fund picking skills (if existent) are diluted by the additional layer of management and incentive fees. The large portion of funds with negative alpha per se (47.50\%) suggests that investment in FoHFs is suboptimal to investing in a diversified portfolio of single-manager hedge funds. And finally, the comparison between real and artificial FoHFs shows that fund picking and strategy timing skills are on average close to non-existent in the first place. 


\section{Appendix 1: DJCS Blue-chip Indices}

Recent years have seen the emergence of investable hedge fund indices. Investable indices are often seen as an alternative to FoHFs. They claim to offer investors better liquidity terms and the advantage of unambiguous portfolio construction, although the last is not necessarily true. In order to assess the performance of FoHFs when regressed on investable indices, we ran a regression using the DJCS Bluechip factors (11 factors). The regression factors are the excess returns on the following indices: the Bluechip DJCS Dedicated Short Bias, Emerging markets, Convertible Arbitrage, Equity Market Neutral, Fixed Income Arbitrage, Long-Short Equity Hedge, Multi-Strategy, Global-Macro, Managed Futures, Event Driven, and Total Hedge funds.

Unfortunately, the period for which we have returns for those indices is not the same as the period used in the non-bluechip DJCS regression in section 5.1. The period of available returns of the DJCS Bluechip factors only starts in August 2003 and ends in August 2009 (6 years). In order to produce a clear comparison, we decided to rerun the 13 -factor nonbluechip DJCS model for the same period for which the bluechip factors are available. Table 15 below provides the results of the two regressions performed on the excess monthly returns of FoHFs with at least 60 months of returns during the period August 2003 to August 2009.

Table 15

Results of the FD procedure on the DJCSBC and DJCS models

(Period: August 2003 - August 2009)

This table is a comparison of the results of the FD procedure as applied to the alpha detected by (Panel A) the DJCS Bluechip model and the (Panel B) the DJCS non-bluechip model

Panel A

\begin{tabular}{|c|c|c|c|}
\hline DJCSBC & Zero-Alpha Funds & Skilled Funds & Unskilled Funds \\
\hline$\%$ & 76,98 & 8,86 & 14,46 \\
\hline Standard Deviation & $4,96 \%$ & $3,48 \%$ & $3,38 \%$ \\
\hline \multicolumn{4}{|c|}{ Panel B } \\
\hline DJCS & Zero-Alpha Funds & Skilled Funds & Unskilled Funds \\
\hline$\%$ & 52,00 & 0,00 & 48,00 \\
\hline Standard Deviation & $7,08 \%$ & $1,16 \%$ & $6,72 \%$ \\
\hline
\end{tabular}

We see that regressing their performance on investable indices produces more favourable results for FoHFs. This result is hardly unexpected given the fact that investable indices usually underperform non-investable ones. Investable indices exclude hedge funds closed to new investments (as the index is investable), as well as other groups of funds such as small funds and niche players. Since investable indices aim at providing frequent liquidity, they also avoid funds with long lock-up periods. Panel A shows the partition among zero-alpha, skilled and unskilled FoHFs resulting from the regression on the bluechip factors. Compared to Panel B, it shows a larger proportion of zero-alpha and skilled funds and a much smaller proportion of unskilled funds. Even though the regression on investable factors shows a shift towards skilled funds, the still very low proportion of skilled funds and 
the large proportion of zero-alpha funds show that there is still progress to be made for the FoHFs industry. 
Appendix 2: Details of the fees structure of our sample of 1'315 FoHFs.

\section{Table 16}

\section{FoHF' fees structure}

The tables below present details of the fees structure of our sample of 1'315 FoHFs

\begin{tabular}{|c|c|c|c|c|c|c|c|c|c|c|}
\hline & \multicolumn{6}{|c|}{ High watermark } & & & & \\
\hline & \multicolumn{3}{|c|}{ Without high watermark } & \multicolumn{3}{|c|}{ With high watermark } & & & & \\
\hline \multirow[t]{3}{*}{ Number of FoHFs } & \multicolumn{3}{|c|}{620} & \multicolumn{3}{|c|}{695} & & & & \\
\hline & \multicolumn{6}{|c|}{ Management fees' distribution } & & & & \\
\hline & $0 \%-1 \%$ & $1 \%-2 \%$ & $2 \%-3 \%$ & $3 \%-4 \%$ & $4 \%-5 \%$ & $5 \%-6 \%$ & & & & \\
\hline \multirow[t]{3}{*}{ Number of FoHFs } & 432 & 818 & 51 & 7 & 4 & 3 & & & & \\
\hline & \multicolumn{10}{|c|}{ Incentive fees' distribution } \\
\hline & $0 \%-5 \%$ & $5 \%-10 \%$ & $10 \%-15 \%$ & $15 \%-20 \%$ & $20 \%-25 \%$ & $25 \%-30 \%$ & $30 \%-35 \%$ & $35 \%-40 \%$ & $40 \%-45 \%$ & $45 \%-50 \%$ \\
\hline Number of FoHFs & 505 & 546 & 82 & 155 & 21 & 5 & 0 & 0 & 0 & 1 \\
\hline
\end{tabular}




\section{Appendix 3: Regression results for the original Fung and Hsieh (2004) and Capocci et al. (2005) models}

Table 17

\section{Regression Statistics for Fung \& Hsieh factors model}

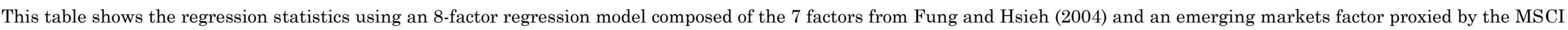

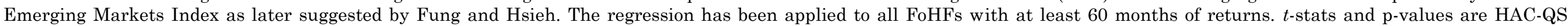
consistent.

\begin{tabular}{|c|c|c|c|c|c|c|c|c|c|c|c|c|}
\hline \multirow[t]{2}{*}{ Number of funds: 280} & \multirow[b]{2}{*}{$\begin{array}{c}\text { Coefficient } \\
\text { (mean } \\
\text { value) } \\
\end{array}$} & \multirow[b]{2}{*}{$\begin{array}{c}t \text {-stat } \\
\text { (mean) }\end{array}$} & \multirow[b]{2}{*}{$\begin{array}{c}\text { p-value } \\
\text { (mean) }\end{array}$} & \multicolumn{3}{|c|}{ All alpha } & \multicolumn{3}{|c|}{ Negative Alpha } & \multicolumn{3}{|c|}{ Positive Alpha } \\
\hline & & & & $\begin{array}{c}\% \text { funds } \\
\text { with } p- \\
\text { value }<5 \%\end{array}$ & $\begin{array}{c}\% \text { funds } \\
\text { with } \mathrm{p}- \\
\text { value }< \\
10 \%\end{array}$ & $\begin{array}{c}\% \text { funds } \\
\text { with p- } \\
\text { value < } \\
20 \% \\
\end{array}$ & $\begin{array}{c}\% \text { funds } \\
\text { with } p- \\
\text { value }<5 \% \\
\end{array}$ & $\begin{array}{c}\% \text { funds } \\
\text { with } \mathrm{p}- \\
\text { value }< \\
10 \%\end{array}$ & $\begin{array}{c}\% \text { funds } \\
\text { with p- } \\
\text { value < } \\
20 \%\end{array}$ & $\begin{array}{c}\% \text { funds } \\
\text { with } p- \\
\text { value }<5 \% \\
\end{array}$ & $\begin{array}{c}\% \text { funds } \\
\text { with } \mathrm{p}- \\
\text { value }< \\
10 \%\end{array}$ & $\begin{array}{c}\% \text { funds } \\
\text { with p- } \\
\text { value < } \\
20 \% \\
\end{array}$ \\
\hline Constant & $-0,001$ & $-0,043$ & $39,89 \%$ & $15,71 \%$ & $22,86 \%$ & $37,50 \%$ & $6,43 \%$ & $11,43 \%$ & $21,79 \%$ & $9,29 \%$ & $11,43 \%$ & $15,71 \%$ \\
\hline D10Y & $-0,448$ & $-0,492$ & $38,73 \%$ & $17,86 \%$ & $26,79 \%$ & $38,93 \%$ & $14,64 \%$ & $20,71 \%$ & $28,57 \%$ & $3,21 \%$ & $6,07 \%$ & $10,36 \%$ \\
\hline DBAA-10Y & $-1,631$ & $-1,455$ & $26,64 \%$ & $35,00 \%$ & $42,86 \%$ & $52,86 \%$ & $33,57 \%$ & $41,07 \%$ & $50,36 \%$ & $1,43 \%$ & $1,79 \%$ & $2,50 \%$ \\
\hline SNP-LIB & $-0,044$ & $-0,462$ & $24,62 \%$ & $38,93 \%$ & $48,21 \%$ & $60,36 \%$ & $24,29 \%$ & $31,79 \%$ & $39,64 \%$ & $14,64 \%$ & $16,43 \%$ & $20,71 \%$ \\
\hline RUL-SP500 & 0,041 & 0,771 & $40,29 \%$ & $19,64 \%$ & $27,14 \%$ & $37,50 \%$ & $1,07 \%$ & $2,50 \%$ & $6,07 \%$ & $18,57 \%$ & $24,64 \%$ & $31,43 \%$ \\
\hline PTFSBD & $-0,011$ & $-0,836$ & $33,79 \%$ & $20,36 \%$ & $30,36 \%$ & $44,64 \%$ & $18,21 \%$ & $26,43 \%$ & $38,21 \%$ & $2,14 \%$ & $3,93 \%$ & $6,43 \%$ \\
\hline PTFSFX & 0,008 & 0,838 & $40,20 \%$ & $15,36 \%$ & $22,50 \%$ & $35,00 \%$ & $0,71 \%$ & $1,07 \%$ & $2,14 \%$ & $14,64 \%$ & $21,43 \%$ & $32,86 \%$ \\
\hline PTFSCOM & 0,005 & 0,220 & $48,46 \%$ & $5,00 \%$ & $11,79 \%$ & $22,14 \%$ & $1,43 \%$ & $4,29 \%$ & $7,14 \%$ & $3,57 \%$ & $7,50 \%$ & $15,00 \%$ \\
\hline \multirow[t]{2}{*}{ MSCIEM-LIB } & 0,165 & 3,842 & $10,66 \%$ & $75,36 \%$ & $78,93 \%$ & $83,57 \%$ & $0,00 \%$ & $0,00 \%$ & $0,00 \%$ & $75,36 \%$ & $78,93 \%$ & $83,57 \%$ \\
\hline & $\begin{array}{l}\text { Mean } \\
\text { Value }\end{array}$ & Min Value & Max Value & & & & & & & & & \\
\hline R-Squared & $47,96 \%$ & $5,06 \%$ & $86,95 \%$ & & & & & & & & & \\
\hline Adjusted R-Squared & $42,61 \%$ & $-8,26 \%$ & $85,18 \%$ & & & & & & & & & \\
\hline Mean MSE & $0,05 \%$ & & & & & & & & & & & \\
\hline
\end{tabular}


Table 18

Regression Statistics for $\mathrm{CCH}$ factors model

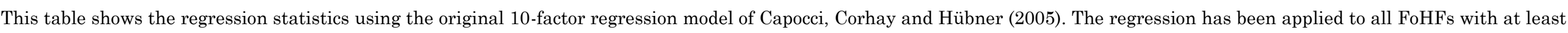
60 months of returns. $t$-stats and p-values are HAC-QS consistent.

\begin{tabular}{|c|c|c|c|c|c|c|c|c|c|c|c|c|}
\hline \multirow[t]{2}{*}{ Number of funds: 280} & \multirow[b]{2}{*}{$\begin{array}{c}\text { Coefficient } \\
\text { (mean } \\
\text { value) } \\
\end{array}$} & \multirow[b]{2}{*}{$\begin{array}{c}t \text {-stat } \\
(\text { mean })\end{array}$} & \multirow[b]{2}{*}{$\begin{array}{l}\text { p-value } \\
\text { (mean) }\end{array}$} & \multicolumn{3}{|c|}{ All alpha } & \multicolumn{3}{|c|}{ Negative Alpha } & \multicolumn{3}{|c|}{ Positive Alpha } \\
\hline & & & & $\begin{array}{c}\% \text { funds } \\
\text { with } \mathrm{p}- \\
\text { value }<5 \%\end{array}$ & $\begin{array}{c}\% \text { funds } \\
\text { with } \mathrm{p}- \\
\text { value }< \\
10 \%\end{array}$ & $\begin{array}{c}\% \text { funds } \\
\text { with } \mathrm{p}- \\
\text { value }< \\
20 \%\end{array}$ & $\begin{array}{c}\% \text { funds } \\
\text { with } p- \\
\text { value }<5 \%\end{array}$ & $\begin{array}{c}\% \text { funds } \\
\text { with } \mathrm{p}- \\
\text { value }< \\
10 \%\end{array}$ & $\begin{array}{c}\% \text { funds } \\
\text { with } \mathrm{p}- \\
\text { value }< \\
20 \%\end{array}$ & $\begin{array}{c}\% \text { funds } \\
\text { with } \mathrm{p}- \\
\text { value }<5 \%\end{array}$ & $\begin{array}{c}\% \text { funds } \\
\text { with } \mathrm{p}- \\
\text { value }< \\
10 \%\end{array}$ & $\begin{array}{c}\% \text { funds } \\
\text { with p- } \\
\text { value < } \\
20 \%\end{array}$ \\
\hline Constant & 0,001 & 1,034 & $35,78 \%$ & $24,29 \%$ & $31,07 \%$ & $43,21 \%$ & $1,07 \%$ & $2,50 \%$ & $4,29 \%$ & $23,21 \%$ & $28,57 \%$ & $38,93 \%$ \\
\hline RUSS3000-LIB & $-0,078$ & $-0,583$ & $27,92 \%$ & $35,71 \%$ & $43,57 \%$ & $53,57 \%$ & $25,71 \%$ & $30,71 \%$ & $36,07 \%$ & $10,00 \%$ & $12,86 \%$ & $17,50 \%$ \\
\hline $\mathrm{SMB}$ & 0,064 & 1,016 & $36,29 \%$ & $21,79 \%$ & $26,79 \%$ & $40,00 \%$ & $0,71 \%$ & $1,07 \%$ & $3,57 \%$ & $21,07 \%$ & $25,71 \%$ & $36,43 \%$ \\
\hline HML & $-0,055$ & $-0,611$ & $33,56 \%$ & $20,36 \%$ & $26,79 \%$ & $43,57 \%$ & $14,64 \%$ & $18,57 \%$ & $31,07 \%$ & $5,71 \%$ & $8,21 \%$ & $12,50 \%$ \\
\hline MOM & 0,074 & 1,966 & $22,60 \%$ & $48,21 \%$ & $54,29 \%$ & $62,14 \%$ & $0,00 \%$ & $0,71 \%$ & $1,43 \%$ & $48,21 \%$ & $53,57 \%$ & $60,71 \%$ \\
\hline MSCIWEUS-LIB & 0,268 & 3,097 & $15,62 \%$ & $65,71 \%$ & $69,64 \%$ & $74,29 \%$ & $0,00 \%$ & $0,00 \%$ & $0,36 \%$ & $65,71 \%$ & $69,64 \%$ & $73,93 \%$ \\
\hline LHMGHY-LIB & 0,131 & 1,279 & $31,04 \%$ & $30,00 \%$ & $36,07 \%$ & $48,21 \%$ & $1,07 \%$ & $2,14 \%$ & $3,57 \%$ & $28,93 \%$ & $33,93 \%$ & $44,64 \%$ \\
\hline JPMEMBI-LIB & $-0,054$ & $-0,419$ & $44,89 \%$ & $7,86 \%$ & $15,71 \%$ & $26,79 \%$ & $6,43 \%$ & $12,86 \%$ & $20,71 \%$ & $1,43 \%$ & $2,86 \%$ & $6,07 \%$ \\
\hline GSCIC-LIB & 0,027 & 0,947 & $35,34 \%$ & $16,79 \%$ & $27,86 \%$ & $44,29 \%$ & $1,07 \%$ & $2,50 \%$ & $4,64 \%$ & $15,71 \%$ & $25,36 \%$ & $39,64 \%$ \\
\hline CWGBI-LIB & $-0,129$ & $-1,088$ & $28,61 \%$ & $25,36 \%$ & $37,14 \%$ & $54,29 \%$ & $23,93 \%$ & $33,93 \%$ & $48,57 \%$ & $1,43 \%$ & $3,21 \%$ & $5,71 \%$ \\
\hline \multirow[t]{2}{*}{ MORTG-LIB } & 0,109 & 0,329 & $47,36 \%$ & $8,93 \%$ & $12,86 \%$ & $25,00 \%$ & $1,07 \%$ & $2,50 \%$ & $6,79 \%$ & $7,86 \%$ & $10,36 \%$ & $18,21 \%$ \\
\hline & $\begin{array}{l}\text { Mean } \\
\text { Value }\end{array}$ & Min Value & Max Value & & & & & & & & & \\
\hline R-Squared & $55,33 \%$ & $6,39 \%$ & $88,35 \%$ & & & & & & & & & \\
\hline Adjusted R-Squared & $49,41 \%$ & $-10,63 \%$ & $86,02 \%$ & & & & & & & & & \\
\hline Mean MSE & $0,05 \%$ & & & & & & & & & & & \\
\hline
\end{tabular}




\section{References}

Agarwal V., Naik N. (2000) Performance Evaluation of Hedge Funds with Option-Based and Buy-andHold Strategies, Working Paper.

Agarwal V., Naik N. (2004) Risks and Portfolio Decisions Involving Hedge Funds, Review of Financial Studies, Vol. 17, No. 1, pp. 63-98.

Andrews D. (1991), Heteroskedasticity and Autocorrelation Consistent Covariance Matrix Estimation. Econometrica, Vol. 59, No. 3, pp. 817-858.

Barras B., Scaillet O., Wermers R. (2010), False Discoveries in Mutual Fund Performance: Measuring Luck in Estimated Alphas, The Journal of Finance, Vol. 65, No. 1, pp. 179-216.

Barras B., Scaillet O., Wermers R. (2008), Internet Appendix to False Discoveries in Mutual Fund Performance: Measuring Luck in Estimated Alphas

Belsley D. A., Kuh E., Welsch R. E. (1980), Regression diagnostics : identifying influential data and sources of collinearity, John Wiley

Berk J., Green R. (2004) Mutual Fund Flows and Performance in Rational Markets, Journal of Political Economy, Vol. 112, No. 6, pp. 1269-1295

Berk J., Green R. (2004) Mutual Fund Flows and Performance in Rational Markets, Journal of Political Economy, Vol. 112, No. 6, pp. 1269-1295

Capocci D., Hübner G. (2004) An Analysis of Hedge Funds Performance, Journal of Empirical Finance, Vol. 11, No. 1, pp. 55-89.

Capocci D., Corhay A., Hübner G. (2005) Hedge Fund Performance and Persistence in Bull and Bear Markets, The European Journal of Finance, Vol. 11, No. 5, 361-392.

Carhart M. (1997) On Persistence in Mutual Fund Performance, Journal of Finance, Vol. 52, No. 1, pp. 57-82.

Séverine Cauchie, Martin Hoesli, Dušan Isakov, The determinants of stock returns in a small open economy, International Review of Economics \& Finance, Volume 13, Issue 2, 2004, Pages 167185.

Criton G., Scaillet O. (2009) Time-Varying Coefficient Model for Hedge Funds, Working Paper, Second Version.

Cuenot, E., \& Reyes, C. (1992). Multi-factor APT model for the Swiss equity market. Credit Suisse Investment Research Basic

Report, Switzerland, Zurich

David Hsieh's website: http://www.duke.edu/ dah7/index.htm.

Fama E., French K. (1993) Common Risk Factors in the Return on Stocks and Bonds, Journal of Financial Economics, Vol. 33, No. 1, pp. 3-56.

Fung W., Hsieh D. (1997) Empirical Characteristics of Dynamic Trading Strategies: The Case of Hedge Funds, The Review of Financial Studies, Vol. 10, No. 2, pp. 275-302

Fung W., Hsieh D. (2000) Performance Characteristics of Hedge Funds and Commodity Funds: Natural versus Spurious Biases, Journal of Financial and Quantitative Analysis, Vol. 35, No. 3, pp. 291-307

Fung W., Hsieh D. (2001) The Risk in Hedge Fund Strategies: Theory and Evidence from Trend Followers, The Review of Financial Studies, Vol. 14, No. 2, pp. 313-341

Fung W., Hsieh D. (2004) Hedge Fund Benchmarks: A Risk-Based Approach, Financial Analysts Journal, Vol. 60, No. 5, pp. 65-80

Fung W., Hsieh D., Naik N., Ramadorai T. (2008) Hedge Funds: Performance, Risk and Capital Formation, The Journal of Finance, Vol. 63, No. 4, pp. 1777-1803

Jensen M. (1968) The Performance of Mutual Funds in the Period 1945-1964, Journal of Finance, Vol. 23, No. 2, pp. 389-416.

Kenneth French's website: http://mba.tuck.dartmouth.edu/pages/faculty/ken.french/ 
Kosowski R., Timmermann A., Wermers R., White H. (2006) Can Mutual Fund "Stars" Really Pick Stocks? New Evidence from a Bootstrap Analysis, The Journal of Finance, Vol. 61, No. 6, pp. 2551-2595.

Liang B. (1999) On the Performance of Hedge Funds, Financial Analysts Journal, Vol. 55, No. 4, pp. $72-85$.

Philipp M. et al. (2009) Performance Rating of Funds of Hedge Funds. Working Paper. Institute of Data Analysis \& Process Design (IDP) and Centre for Alternative Investments \& Risk Management (ZAI) of the Zurich University of Applied Sciences (ZHAW)

Sharpe W. (1992) Asset Allocation: Management Style and Performance Measurement, Journal of Portfolio Management, Vol. 18, No. 2, pp. 7-19.

Storey J. (2002) A Direct Approach to False Discovery Rates, Journal of the Royal Statistical Society. Series B (Statistical Methodology), Vol. 64, No. 3, pp. 479-498. 